OPEN ACCESS

Edited by:

Daniel Zaldivar,

National Institute of Mental Health, National Institutes of Health $(\mathrm{NIH})$,

United States

Reviewed by:

Jose L. Herrero,

Feinstein Institute for Medical Research, United States

Guillermo Gonzalez-Burgos, University of Pittsburgh, United States

*Correspondence: Maria Medalla mmedalla@bu.edu

Received: 14 October 2021 Accepted: 09 December 2021

Published: 11 January 2022

Citation:

Tsolias A and Medalla M (2022) Muscarinic Acetylcholine Receptor Localization on Distinct Excitatory and Inhibitory Neurons Within the ACC and LPFC of the Rhesus Monkey. Front. Neural Circuits 15:795325. doi: 10.3389/fncir.2021.795325

\section{Muscarinic Acetylcholine Receptor Localization on Distinct Excitatory and Inhibitory Neurons Within the ACC and LPFC of the Rhesus Monkey}

\author{
Alexandra Tsolias ${ }^{1}$ and Maria Medalla ${ }^{1,2 *}$ \\ ${ }^{1}$ Department of Anatomy \& Neurobiology, Boston University School of Medicine, Boston, MA, United States, ${ }^{2}$ Center for \\ Systems Neuroscience, Boston University, Boston, MA, United States
}

Acetylcholine (ACh) can act on pre- and post-synaptic muscarinic receptors (mAChR) in the cortex to influence a myriad of cognitive processes. Two functionally-distinct regions of the prefrontal cortex - the lateral prefrontal cortex (LPFC) and the anterior cingulate cortex (ACC) - are differentially innervated by ascending cholinergic pathways yet, the nature and organization of prefrontal-cholinergic circuitry in primates are not well understood. Using multi-channel immunohistochemical labeling and high-resolution microscopy, we found regional and laminar differences in the subcellular localization and the densities of excitatory and inhibitory subpopulations expressing $\mathrm{m} 1$ and m2 muscarinic receptors, the two predominant cortical mAChR subtypes, in the supragranular layers of LPFC and ACC in rhesus monkeys (Macaca mulatta). The subset of $\mathrm{m}^{+} / \mathrm{m}^{+}$expressing SMl-32 $2^{+}$pyramidal neurons labeled in layer 3 (L3) was denser in LPFC than in ACC, while $\mathrm{m} 1^{+} / \mathrm{m}^{+}$SMl-32 ${ }^{+}$neurons co-expressing the calcium-binding protein, calbindin (CB) was greater in ACC. Further, we found between-area differences in laminar $\mathrm{m}^{+}$dendritic expression, and $\mathrm{m} 2^{+}$presynaptic localization on cortico-cortical (VGLUT1 $1^{+}$) and sub-cortical inputs $\left(\mathrm{VGLUT2}^{+}\right)$, suggesting differential cholinergic modulation of top-down vs. bottom-up inputs in the two areas. While almost all inhibitory interneurons-identified by their expression of parvalbumin $\left(\mathrm{PV}^{+}\right), \mathrm{CB}^{+}$, and calretinin $\left(\mathrm{CR}^{+}\right)$-expressed $\mathrm{m}^{+}$, the localization of $\mathrm{m}^{+}$differed by subtype and area. The ACC exhibited a greater proportion of $\mathrm{m}^{+}$inhibitory neurons compared to the LPFC and had a greater density of presynaptic $\mathrm{m}^{+}$localized on inhibitory $\left(\mathrm{VGAT}^{+}\right)$inputs targeting proximal somatodendritic compartments and axon initial segments of $L 3$ pyramidal neurons. These data suggest a greater capacity for $\mathrm{m} 2^{+}$-mediated cholinergic suppression of inhibition in the ACC compared to the LPFC. The anatomical localization of muscarinic receptors on ACC and LPFC micro-circuits shown here contributes to our understanding of diverse cholinergic neuromodulation of functionally-distinct prefrontal areas involved in goal-directed behavior, and how these interactions maybe disrupted in neuropsychiatric and neurological conditions.

Keywords: acetylcholine, muscarinic receptors, prefrontal cortex, non-human primate, inhibitory neurons, microcircuit 


\section{INTRODUCTION}

Ascending brainstem neuromodulatory inputs to the prefrontal cortex (PFC) play an important role in the control of arousal and motivation during executive function and decision making (Mesulam et al., 1984; Everitt and Robbins, 1997; Picciotto et al., 2012). Acetylcholine (ACh), one such neuromodulator, plays a key role in both memory and emotional processing as well as PFC-mediated higher-order cognitive functions (Barbas, 2000; Hasselmo and Sarter, 2011). Behavioral studies have shown that cholinergic stimulation of the PFC enhanced cognitive performance in attention and working memory tasks in rodents (Deutsch, 1971), rhesus monkeys (Taffe et al., 1999; Vijayraghavan et al., 2018; Vijayraghavan and Everling, 2021), and humans (Drachman and Leavitt, 1974; Broks et al., 1988). Studies in rhesus monkeys have also shown that cholinergic muscarinic receptor antagonist, scopolamine (Bartus and Johnson, 1976) or deafferentation of cholinergic inputs to PFC (Croxson et al., 2011) produced deficits in delayed-response working memory tasks. Conversely, procholinergic drugs such as cholinesterase inhibitors ameliorated cognitive deficits seen in neurodegenerative disorders (Hampel et al., 2018; Moss, 2020). While these studies highlight the importance of ACh on PFC-mediated executive functions, the cellular and molecular effects of ACh in functionally-distinct PFC areas in primates remain unclear.

In primates, two key components of the frontal executive network - the lateral prefrontal cortex (LPFC) and the anterior cingulate cortex (ACC)-are markedly distinct with regard to the patterns of cholinergic innervation (Mesulam et al., 1984; Ghashghaei and Barbas, 2001). Cholinergic projections are significantly denser in limbic cortices, such as the ACC, compared to the LPFC (Mash et al., 1988; Ghashghaei and Barbas, 2001). The medially-located ACC has robust connectivity with limbic structures, such as the amygdala and hippocampus, and is therefore critical for motivational processing and cognitive-emotional interactions (Devinsky et al., 1995; Miller and Cohen, 2001; Barbas and Zikopoulos, 2007). However, the effects of cholinergic modulation on in vivo neuronal activity in primates have mostly been studied in LPFC, which is involved in sensory-motor processing and maintenance of relevant information in working memory (Barbas, 2000; Levy and Goldman-Rakic, 2000). Systemic treatment with the cholinergic muscarinic antagonist, scopolamine, diminished delay-related neuronal firing in LPFC during working memory tasks (Zhou et al., 2011; Major et al., 2015). Iontophoretic application of ACh within LPFC frontal eye fields resulted in increased neuronal task-related firing rates of diverse cell types (Dasilva et al., 2019). While cholinergic pathways have been shown to differentially alter intrinsic neuronal excitability and synaptic signaling in specific areas, layers, and cell types in rodent cortices (Parikh et al., 2007; Obermayer et al., 2017), the distribution of cholinergic receptors on distinct cell types in the primate LPFC and ACC remains unknown.

Pyramidal neurons in supragranular layers 2-3 of the PFC are principally responsible for cortico-cortical communication underlying cognitive processing (Barbas, 1986; Gonzalez-Burgos et al., 2000; Constantinidis et al., 2001; Amatrudo et al., 2012). Our previous work has shown that layer 3 (L3) pyramidal neurons in LPFC and ACC differ significantly in their inhibitory inputs (Medalla et al., 2017). Local GABAergic inhibitory interneurons, which constitute $\sim 20-30 \%$ of all cortical neurons (Dombrowski et al., 2001), consist of diverse subtypes identified by their expression of calcium-binding proteins, parvalbumin $(\mathrm{PV})$, calbindin (CB), and calretinin (CR), in primates (DeFelipe, 1997; Markram et al., 2004). PV neurons confer strong inhibition by targeting the proximal dendrites, somata, or axon initial segments of other neurons (DeFelipe, 1997; Kawaguchi and Kubota, 1998). On the other hand, CB neurons preferentially synapse on distal dendrites and spines (DeFelipe, 1997), similar to somatostatin-expressing interneurons in rodents (Rogers, 1992; Rocco et al., 2016). CR neurons synapse on other inhibitory neurons and have a dis-inhibitory role (del Rio and DeFelipe, 1997), analogous to VIP-expressing interneurons in rodents (Rogers, 1992; Gabbott and Bacon, 1997; Rocco et al., 2016). The ACC and LPFC differ markedly in the distribution of these neurochemical interneuron classes (Dombrowski et al., 2001). The neuromodulation of excitatory:inhibitory (E:I) balance shape functional circuitry in these PFC areas during behavior.

In primate and rodent cortices, $\mathrm{ACh}$ acts mainly through volume transmission (Mrzljak et al., 1995; Descarries and Mechawar, 2000; Sarter et al., 2009) and binds to muscarinic or nicotinic receptors extra-synaptic to cholinergic synapses, which are localized within or near glutamatergic and GABAergic synaptic sites (Sarter et al., 2009; Colangelo et al., 2019). Metabotropic G-protein coupled muscarinic acetylcholine receptors ( $\mathrm{mAChR}$ ), $\mathrm{m} 1$ and $\mathrm{m} 2$, are the predominant subtypes in the rhesus monkey cortex (Mrzljak et al., 1993; Picciotto et al., 2012). The $\mathrm{m} 1$ receptor, the main subtype expressed in the primate PFC, exerts a depolarizing effect on excitatory and inhibitory neurons when bound to $\mathrm{ACh}$, and is localized on dendrites and spines, post-synaptic to glutamatergic and GABAergic synapses (Mrzljak et al., 1993; Carr and Surmeier, 2007). By contrast, the $\mathrm{m} 2$ receptor is largely located pre-synaptically on cortical glutamatergic and GABAergic nerve terminals, suppressing neurotransmitter release (Mrzljak et al., 1993; Kimura and Baughman, 1997; Salgado et al., 2007). Thus, the subcellular localization of $\mathrm{m} 1$ or $\mathrm{m} 2$ receptors underlies the functional consequences of cholinergic activation by fine-tuning E:I circuitry and activity during information processing (Picciotto et al., 2012; Groleau et al., 2015). However, the receptor and cell-type specific effects of ACh in ACC and LPFC remain largely unknown. Iontophoresis of an $\mathrm{m} 1$ receptor agonist into LPFC suppressed neuronal activity and overstimulation of $\mathrm{m} 1$ disrupted rule representations during a working memory task (Vijayraghavan et al., 2018). However, in the same area, $\mathrm{m} 1 \mathrm{mAChR}$ blockade (Vijayraghavan et al., 2018) and muscarinic stimulation increased the firing of both broad spiking and narrow spiking cell types (Dasilva et al., 2019). While these in vivo data point to diverse effects of $\mathrm{ACh}$ on physiologically-distinct task-related cell types, the involvement of excitatory or inhibitory neuronal classes, which cannot be distinguished reliably in vivo (Lee et al., 2021), remain unclear. Because anatomical structure constrains function, the goal of 
the current study is to determine the extent to which $\mathrm{m} 1$ and $\mathrm{m} 2$ receptors are expressed across distinct excitatory and inhibitory subpopulations and subcellular compartments in the ACC and LPFC. The anatomical localization of muscarinic receptors on these micro-circuits contributes to our understanding of prefrontal cholinergic neuromodulation and how this maybe be disrupted in neuropsychiatric and neurological conditions.

\section{MATERIALS AND METHODS}

\section{Experimental Subjects}

Brain tissue used in this study was obtained from six young rhesus monkeys of both sexes (Macaca mulatta; $9 \pm 1.13$ years; two females and four males) that were a part of a larger program of studies on brain aging and cognition. Monkeys were obtained from National Primate Centers and private vendors and housed individually in the Laboratory Animal Science Center at Boston University School of Medicine; the facilities are fully accredited by the Association for Assessment and Accreditation of Laboratory Animal Care, with animal research conducted in strict accordance with guidelines of the National Institutes of Health's Guide for the Care and Use of Laboratory Animals and Public Health Service Policy on Humane Care and Use of Laboratory Animals.

\section{Perfusion and Preparation of Tissue}

Tissue was harvested using our well-established two-stage perfusion protocol allowing for the harvest of both live tissue and fixed tissue (Amatrudo et al., 2012) for parallel experiments not in the present study. After sedation with ketamine hydrochloride $(10 \mathrm{mg} / \mathrm{kg}$ ) the monkeys were deeply anesthetized with sodium pentobarbital (to effect, $15 \mathrm{mg} / \mathrm{kg}$, i.v), and then perfused through the ascending aorta with ice-cold Krebs-Henseleit buffer containing (in mM): $6.4 \mathrm{Na}_{2} \mathrm{HPO}_{4}, 1.4 \mathrm{Na}_{2} \mathrm{PO}_{4}, 137 \mathrm{NaCl}$, $2.7 \mathrm{KCl}, 5$ glucose, $0.3 \mathrm{CaCl}_{2}$, and $1 \mathrm{MgCl}_{2}, \mathrm{pH} 7.4$ (SigmaAldrich). Fresh tissues were collected from the left hemisphere for parallel biochemical and electrophysiological studies not in the present study. Once the fresh tissue harvest was complete, the perfusate was switched to $4 \%$ paraformaldehyde in $0.1 \mathrm{M}$ phosphate buffer $\left(\mathrm{PB}\right.$, ph 7.4 , at $\left.37^{\circ} \mathrm{C}\right)$ to fix the remaining whole brain. The fixed brain sample was blocked, in situ, in the coronal plane, removed from the skull, cryoprotected in a series of glycerol solutions, and flash-frozen in $-70^{\circ} \mathrm{C}$ isopentane (Rosene et al., 1986). The brain was cut on a freezing microtome in the coronal plane at 30 or $60 \mu \mathrm{m}$ and stored in cryoprotectant (15\% glycerol, in $0.1 \mathrm{M} \mathrm{PB}, \mathrm{pH} 7.4$ ) at $-80^{\circ} \mathrm{C}$ (Estrada et al., 2017).

\section{Tissue Processing and Immunohistochemical Labeling for Fluorescent Microscopy}

To visualize the distribution and extent of colocalization of $\mathrm{m} 1$ and $\mathrm{m} 2$ with distinct interneurons, pyramidal neurons, and inhibitory or excitatory vesicular transporter proteins, we batch processed 2-3 serial coronal $30 \mu \mathrm{m}$ tissue sections through the ACC and LPFC per case for immunolabeling experiments adapted from (Medalla et al., 2017). Free-floating tissue sections were first rinsed $\left(3 \times 10 \mathrm{~min}, 4^{\circ} \mathrm{C}\right)$ in $0.01 \mathrm{M}$ phosphate-buffered saline (PBS) and incubated in $50 \mathrm{mM}$ glycine for $1 \mathrm{~h}$ at $4^{\circ} \mathrm{C}$. Sections were then rinsed in $0.01 \mathrm{M}$ PBS $\left(3 \times 10 \mathrm{~min}, 4^{\circ} \mathrm{C}\right)$, and antigen retrieval was performed with $10 \mathrm{mM}$ sodium citrate $(\mathrm{pH} 8.5)$ in a $60-70^{\circ} \mathrm{C}$ water bath for $20 \mathrm{~min}$. Sections were then rinsed in $0.01 \mathrm{M}$ PBS $\left(3 \times 10 \mathrm{~min}, 4^{\circ} \mathrm{C}\right)$ and incubated in pre-block (0.01 M PBS, 5\% bovine serum albumin (BSA), $5 \%$ normal donkey serum (NDS), $0.2 \%$ Triton X-100) to reduce any non-specific binding of secondary antibodies. Sections were incubated at $4^{\circ} \mathrm{C}$ for $48 \mathrm{~h}$ in a combination of primary antibodies to label distinct cell types with muscarinic receptors (see Table 1, diluted in $0.1 \mathrm{M} \mathrm{PB}, 0.2 \%$ acetylated BSA (BSA-c, Aurion), $1 \%$ NDS, $0.1 \%$ Triton X-100) as follows: (1) PV, CR, $\mathrm{m} 1 / \mathrm{m} 2$; (2) CB, SMI-32, VGAT, m1/m2; (3) MAP2, VGAT, m1, m2; and (4) VGLUT1, VGLUT2, m2. To increase the penetration of the antibodies, two incubation sessions in a low-wattage microwave $(2 \times 10 \mathrm{~min}$ at $150 \mathrm{~W})$ using the Pelco Biowave Pro (Ted Pella), followed by a 48 -h incubation at $4^{\circ} \mathrm{C}$ with gentle agitation were employed. After rinsing $(3 \times 10 \mathrm{~min})$ in $0.01 \mathrm{M}$ PBS at $4^{\circ} \mathrm{C}$, sections were incubated overnight in secondary antibodies diluted in incubation buffer (see Table 2) microwaved $2 \times 10 \mathrm{~min}$ at $150 \mathrm{~W}$ (Ted Pella Pelco Biowave), and placed at $4^{\circ} \mathrm{C}$ for $24 \mathrm{~h}$ with gentle agitation. In some immunolabeling batches, biotinylated secondary antibodies and Streptavidin 546 conjugates were used to further amplify $\mathrm{m} 2$ labeling. Sections were then rinsed $(3 \times 10 \mathrm{~min})$ in $0.1 \mathrm{M} \mathrm{PB}$, mounted onto glass slides and cover-slipped with prolonged anti-fade gold mounting medium (ThermoFisher), and cured at room temperature in the dark. Control experiments performed included omitting the primary antibody or pre-absorbing the primary antibody with a control peptide were conducted and yielded no labeling. Additionally, density counts in the primary visual area (V1) yielded densities similar to those reported in (Disney and Aoki, 2008; data not shown).

\section{Confocal Microscopy and Visualization of Immunofluorescent Labeling}

Immunofluorescent labeling was imaged at high resolution using a laser-scanning confocal microscope (Leica SPE or Zeiss LSM 710). Image stacks were acquired using a plan apochromat $40 \times / 1.3 \mathrm{NA}$ oil-immersion objective at a resolution of $0.268 \mu \mathrm{m} \times 0.268 \mu \mathrm{m} \times 0.5 \mu \mathrm{m}$ (Leica TCS SPE) or $0.208 \times 0.208 \times 0.5 \mu \mathrm{m}$ (Zeiss LSM 710) voxel size. Based on architectonic maps of prefrontal cortices (Barbas and Pandya, 1989), medial area 24 of ACC and dorsal area 46 of LPFC were identified and imaged in a columnar fashion from the pial surface to the white matter boundary (three columns per area and case). The resulting image stacks were deconvolved to improve the signal-to-noise ratio and converted to 8-bit images for analysis using AutoQuant (Media Cybernetics).

\section{Interneuron and Pyramidal Cell Density Estimates}

We quantified the density of immunolabeled somata of total $\mathrm{mAChR} \mathrm{m}^{+}$and $\mathrm{m} 2^{+}$labeled cells and subpopulations of excitatory $\left(\mathrm{MAP}^{+}, \mathrm{SMI}^{-32^{+}}\right)$and inhibitory $\left(\mathrm{CB}^{+} \mathrm{PV}^{+} \mathrm{CR}^{+}\right)$ 
TABLE 1 | Primary antibodies utilized in immunohistochemistry.

\begin{tabular}{|c|c|c|c|c|}
\hline Primary Antibody & Host & Dilution & Vendor, Catalog \# & RRID \\
\hline Calbindin D-28k (CB) & Rabbit & $1: 2,000$ & Swant, CB38 & AB_10000340 \\
\hline Calretinin D-28K (CR) & Rabbit & $1: 2,000$ & Swant, 7697 & AB_2721226 \\
\hline Parvalbumin (PV) & Guinea Pig & $1: 2,000$ & Swant, GP72 & AB_2665495 \\
\hline Microtubule associated protein-2 (MAP2) & Chicken & $1: 1,000$ & Abcam, ab5392 & AB_2138153 \\
\hline Neurofilament H non-phosphorylated (SMI32) & Mouse & $1: 2,000$ & BioLegend, 801701 & AB_2564642 \\
\hline Muscarinic Receptor 1 (m1) & Goat & $1: 500$ & Abcam, ab77098 & AB_1523990 \\
\hline Muscarinic Receptor 2 (m2) & Rat & $1: 500$ & Millipore, MAB367 & AB_94952 \\
\hline Vesicular GABAergic Transporter (VGAT) & Guinea Pig & $1: 400$ & Synaptic Systems, 131004 & AB_887873 \\
\hline Vesicular Glutamate Transporter (VGLUT1) & Rabbit & $1: 1,000$ & Synaptic Systems, 135303 & AB_887875 \\
\hline Vesicular Glutamate Transporter (VGLUT2) & Guinea Pig & $1: 1,000$ & Synaptic Systems, 135404 & AB_887884 \\
\hline
\end{tabular}

TABLE 2 | Secondary antibodies utilized in immunohistochemistry.

\begin{tabular}{|c|c|c|c|}
\hline Secondary antibody conjugate & Host-antigen & Dilution & Vendor, Catalog \# \\
\hline Alexa 405 & Donkey anti-mouse & $1: 200$ & ThermoFisher, A10036 \\
\hline Alexa 488 & Donkey anti- Guinea Pig & $1: 200$ & Jackson, 706-545-148 \\
\hline Alexa 488 & Donkey anti-chicken & $1: 200$ & Jackson, 703-545-155 \\
\hline Alexa 546 & Donkey anti- Rabbit & $1: 200$ & Thermofisher, A10040 \\
\hline Alexa 647 & Donkey anti- Guinea Pig & $1: 200$ & Jackson, 706-605-148 \\
\hline Alexa 633 & Donkey anti-goat & $1: 200$ & Thermofisher, A21082 \\
\hline Alexa 647 & Donkey anti-rat & $1: 200$ & Jackson, 712-606-150 \\
\hline Biotin & Donkey anti-rat & $1: 200$ & Jackson, 712-067-003 \\
\hline Streptavidin-546 & $\begin{array}{l}\text { Biotinylated Donkey } \\
\text { anti-Rat }\end{array}$ & $1: 200$ & ThermoFisher, S11225 \\
\hline
\end{tabular}

neurons co-expressing $\mathrm{m}^{+}$and $\mathrm{m}^{+}$using adapted stereologic cell counting procedures (Fiala and Harris, 2001). The different cortical layers were delineated based on depth from the pial surface measured from matched Nissl sections. Fields imaged within layer 2 (L2) and layer 3 (L3) in each area were counted separately. Image stacks were deconvolved (AutoQuant, Media Cybernetics) and imported into FIJI ${ }^{1}$ (1997-2016). Each image acquired was a counting field of about $212.5 \mu \mathrm{m} \times 212.5 \mu \mathrm{m}$ area and $18 \mu \mathrm{m}$ in depth. To quantify the density of total singlelabeled $\mathrm{m}^{+}$and $\mathrm{m}^{+}$cells, the individual $\mathrm{m} 1$ or $\mathrm{m} 2$ channels were extracted from each multi-channel image from five sets of immunolabeling experiments: (1) PV, CR, m1; (2) PV, CR, m2; (3) CB, SMI-32, VGAT, m1; (4) CB, SMI-32, VGAT, m2; and (5) MAP2, VGAT, m1, m2. Each single channel $\mathrm{m} 1$ or $\mathrm{m} 2$ image was taken as a sampling site, and cell densities across all images were averaged per case. Pyramidal vs. non-pyramidal neurons were identified based on morphology, as well as staining with $\mathrm{MAP}^{+}, \mathrm{SMI}_{3}{ }^{+}$, and $\mathrm{CB}^{+}$. Morphologically identified pyramidal neurons were based on classic criteria, which included the pyramidal-shaped cell body and the prominent apical dendrite (Spruston, 2008). For $\mathrm{CB}^{+}$, non-pyramidal interneurons were distinguished morphologically and counted separately from $\mathrm{CB}^{+}$pyramidal neurons. Immunolabeled cell bodies were manually counted using FIJI software and the "cell counter" plug-in marking single-labeled somata expressing particular excitatory and inhibitory markers and the subset dual-labeled with mAChRs. Volumetric stereological counting rules were implemented with inclusion/exclusion criteria to avoid counting a cell soma more than once due to the inherent errors of cell plucking and cell splitting during sectioning, as described

\footnotetext{
${ }^{1}$ http://imagej.nih.gov/ij/
}

(Schmitz and Hof, 2005). Neuronal cell bodies touching the inclusion borders ( $\mathrm{x}-\mathrm{y}$ top and right border of the image, and the topmost optical $\mathrm{z}$ slice) of the image were counted, while those touching exclusion borders were omitted. The resulting raw data counts were expressed as a density measure (neurons $/ \mathrm{mm}^{3}$ ) in each cortical layer and area to yield four values per animal and marker as follows: ACC L2, ACC L3, LPFC L2, LPFC L3.

\section{Quantification and Colocalization of mAChR ${ }^{+}$Puncta Total Labeled Puncta in Neuropil}

We assessed the total optical density of either muscarinic receptors $(\mathrm{m} 1, \mathrm{~m} 2)$ puncta or synaptic markers (VGAT, VGLUT1, VGLUT2) in the neuropil using the particle analysis function in FIJI/Image ${ }^{2}$ (1997-2016); RRID:SCR_002285 (Schindelin et al., 2012). The signal threshold was determined using either the Otsu or Renyi method and was applied to all images per case. The average measure of receptor or synaptic puncta optical density was calculated for L1-L3 and expressed as percent area labeled (Schneider et al., 2012).

\section{Colocalization of mAChR With Pyramidal Neuron Somatic and Dendritic Postsynaptic Compartments}

We used the ROI manager and colocalization plug-in in FIJI to quantify the colocalization of $\mathrm{mAChR}^{+}$on distinct somatic and dendritic compartments of labeled excitatory pyramidal neurons (MAP2, SMI-32). The segmentation editor and ROI manager in FIJI were used to isolate the somatic and dendritic compartments (ACC $n=10$ soma/dendrite, LPFC $n=10$ soma/dendrite) of morphologically identified MAP2 ${ }^{+}$pyramidal neurons in L3. The density of $\mathrm{mAChR}^{+}$within these identified $\mathrm{MAP}^{+}$ROIs was

\footnotetext{
${ }^{2}$ https://imagej.net/Fiji
} 
performed by using particle analyses to estimate the percent area labeled within each ROI (Schneider et al., 2012).

\section{Colocalization of $\mathrm{m}^{+}$Puncta on Excitatory and Inhibitory Presynaptic Terminals}

We estimated the extent of pre-synaptic localization of the $\mathrm{m}^{+}$receptor on excitatory and inhibitory axon terminals by dual-labeling of $\mathrm{m}^{+}$with excitatory and inhibitory presynaptic markers: vesicular glutamatergic $\left(\mathrm{VGLUT1}^{+}\right.$and $\mathrm{VGLUT2}^{+}$) and GABAergic $\left(\mathrm{VGAT}^{+}\right)$transporter proteins. Additionally, in L1 and L3 of ACC and LPFC, we performed a triplecolocalization to examine the proportion of $\mathrm{CB}^{+}$and $\mathrm{PV}^{+}$ $\mathrm{VGAT}^{+}$axon terminals colocalized with $\mathrm{m}^{+}$. We used the particle analysis function (Schneider et al., 2012) followed by the FIJI EZ colocalization plug-in (Stauffer et al., 2018) to calculate the degree of colocalized pixels in the neuropil using the Mander's overlap coefficient, as previously described (Medalla and Luebke, 2015; LeBlang et al., 2020; ACC $n=6$ cases, LPFC $n=6$ cases). Colocalization was calculated based on Mander's colocalization coefficients, which is the ratio of percent area colocalized over the percent area of either channel 1 or channel 2 (Stauffer et al., 2018).

\section{Colocalization of $\mathrm{m}^{+}$Puncta on Compartment-Specific Inhibitory Presynaptic Terminals}

In the $\mathrm{VGAT}^{+}$labeled tissue, we assessed whether inhibitory inputs to specific pyramidal neurons compartments express $\mathrm{m}^{+}$. We performed triple colocalization of $\mathrm{VGAT}^{+} \mathrm{m} 2^{+}$with a marker for pyramidal neurons $\left(\mathrm{MAP}^{+}\right.$or $\mathrm{SMI}-32^{+}$), using a colocalization plug-in followed by particle analyses in FIJI. We selected a random set of $\mathrm{L} 3 \mathrm{MAP}^{+}$labeled pyramidal neurons, delineated the proximal apical dendritic and somatic ROIs (as above), and ran the colocalization plug-in to create a mask of colocalized $\mathrm{VGAT}^{+}$with $\mathrm{m} 2^{+}$puncta. Then, the percent area of these dual labeled $\mathrm{VGAT}^{+} \mathrm{m}^{+}$puncta within each $\mathrm{MAP}^{+}$ROI was calculated using particle analyses. For SMI- $32^{+}$pyramidal neurons, we selected a subset with a visible somatic and dendritic label, ran the colocalization plug-in in FIJI to visualize colocalized points, and manually counted dual-labeled $\mathrm{VGAT}^{+} \mathrm{m}^{+}$puncta along SMI- $32^{+}$pyramidal somata and proximal apical dendritic trunks (first $100 \mu \mathrm{m}$ ) using Neurolucida 360 software (MBF Biosciences). Puncta were identified as $\mathrm{VGAT}^{+} \mathrm{m}^{+}$or $\mathrm{VGAT}^{+}$ only (ACC $n=10$ neurons, LPFC $n=10$ neurons). Puncta identified on the soma were normalized to the surface area while those on the dendrite were normalized to length.

We analyzed the density and length of $\mathrm{VGAT}^{+}$axon "cartridges" in L2-3 of ACC and LPFC and their colocalization with $\mathrm{m}^{+}$. Using Neurolucida 360 (MBF Biosciences), VGAT ${ }^{+}$ cartridges were identified as rows of puncta perpendicular to the pial surface (Somogyi, 1977), and counted using stereological counting procedures, and classified depending on their strength of $\mathrm{m}^{+}$expression as follows: strongly labeled $\mathrm{m}^{++} \mathrm{VGAT}^{+}\left(>50 \%\right.$ of $\mathrm{VGAT}^{+}$cartridge area labeled was colocalized with $\mathrm{m} 2$ ); lightly-labeled $\mathrm{m}^{+} \mathrm{VGAT}^{+}(\leq 50 \%$ of $\mathrm{VGAT}^{+}$cartridge area labeled was colocalized with $\left.\mathrm{m} 2\right)$; or $\mathrm{m}^{-}$ $\mathrm{VGAT}^{+}$. The density and proportion of each "cartridge type" were compared between areas. For each case, we exhaustively measured the length of individual $\mathrm{VGAT}^{+}$cartridges in LPFC ( $n=300$ cartridges measured from six cases) and ACC ( $n=200$ cartridges from five cases). The measured lengths were averaged for each case and compared between areas. A subset of the VGAT cartridge types classified as lightly $\mathrm{m}^{+}$labeled and strongly $\mathrm{m}^{++}$labeled was further measured for length and analyzed for proportion and densities (number per length of the cartridge) of individual VGAT ${ }^{+} \mathrm{m}^{-}$and $\mathrm{VGAT}^{+} \mathrm{m}^{+}$boutons along each cartridge.

\section{Statistical Analyses}

All statistical analyses were conducted in MATLAB (Mathworks, Natick, MA). An outlier analysis and tests for normality (Zscore calculation and Kolmogorov-Smirnov test) were performed for each outcome measure and group. Between-area (ACC vs. LPFC) and between-layer (L1, L2, L3) comparisons of outcome measures were conducted using a Two-Way ANOVA (for layer $x$ area and $\mathrm{mAChR} \times$ layer within area) with a Fisher's Least Significant Difference (LSD) post hoc analysis. Comparisons between somatodendritic compartments by area were performed using a multiple comparisons One-Way ANOVA with a Fisher's Least Significant Difference (LSD) post hoc analysis. Between and within groups statistical comparisons of frequency distributions were performed using Chi-Squared tests and corrected for multiple comparisons using the Bonferroni method.

\section{RESULTS}

We assessed the overall density distribution of the total cells expressing $\mathrm{m}^{+}, \mathrm{m}^{+}$or both $\mathrm{m}^{+} \mathrm{m}^{+}$within $\mathrm{L} 2$ and $\mathrm{L} 3$ of ACC area 24 and of LPFC area 46 (Figure 1). Within the ACC, $\mathrm{m}^{+}$cells were significantly greater than cells expressing $\mathrm{m}^{+}$ in L3 ( $p=0.04$, Two- Way ANOVA, Fisher's LSD post hoc) and co-expressing $\mathrm{m}^{+} \mathrm{m} 2^{+}$in L2 $(p=0.01)$. While in LPFC $\mathrm{L} 2$ and $\mathrm{L} 3, \mathrm{m1}^{+}$cells were significantly greater than $\mathrm{m}^{+}$(L2: $\left.p=3.08 \times 10^{-4}, \mathrm{~L} 3: p=9.47 \times 10^{-5}\right)$ and $\mathrm{m}^{+} \mathrm{m}^{+}$cells (L2: $p=2.97 \times 10^{-3}$, L3: $\left.p=1.82 \times 10^{-3}\right)$. Two-way ANOVA comparisons revealed significant between-area differences for $\mathrm{m} 1$ cells and within-area (between-layer) differences for $\mathrm{m}^{+}$ cells. LPFC L2 and L3 had a significantly greater $\mathrm{m}^{+}$cell density compared to ACC (LPFC vs. ACC L2: $p=9.37 \times 10^{-3}$, LPFC vs. ACC L3: $p=8.53 \times 10^{-3}$; Figure 1C). Within both ACC and LPFC, the density of $\mathrm{m}^{+}$cells was significantly greater in L2 compared to L3 (ACC L2 vs. L3: $p=1.09 \times 10^{-4}$, LPFC L2 vs. L3: $p=1.43 \times 10^{-3}$; Figure 1D). No significant differences in the density of co-expression of $\mathrm{m}^{+} \mathrm{m}^{+}$receptors within or between areas were found (Figure 1E). Of the total $\mathrm{m}^{+}, \mathrm{m}^{+}$, or $\mathrm{m}^{+} \mathrm{m}^{+}$expressing cells within these areas and layers, $52-77 \%$ were identified as pyramidal, based on morphology, and the rest were non-pyramidal (Figures 1F-H).

\section{Distribution of $\mathrm{m}^{+}$and $\mathrm{m}^{+}$Expressing MAP2 ${ }^{+}$Pyramidal Neuron in ACC and LPFC} We used the cytoskeletal protein MAP2, which strongly labels somata and dendrites of excitatory pyramidal neurons (Caceres et al., 1984; Peters and Sethares, 1991), and quantified 

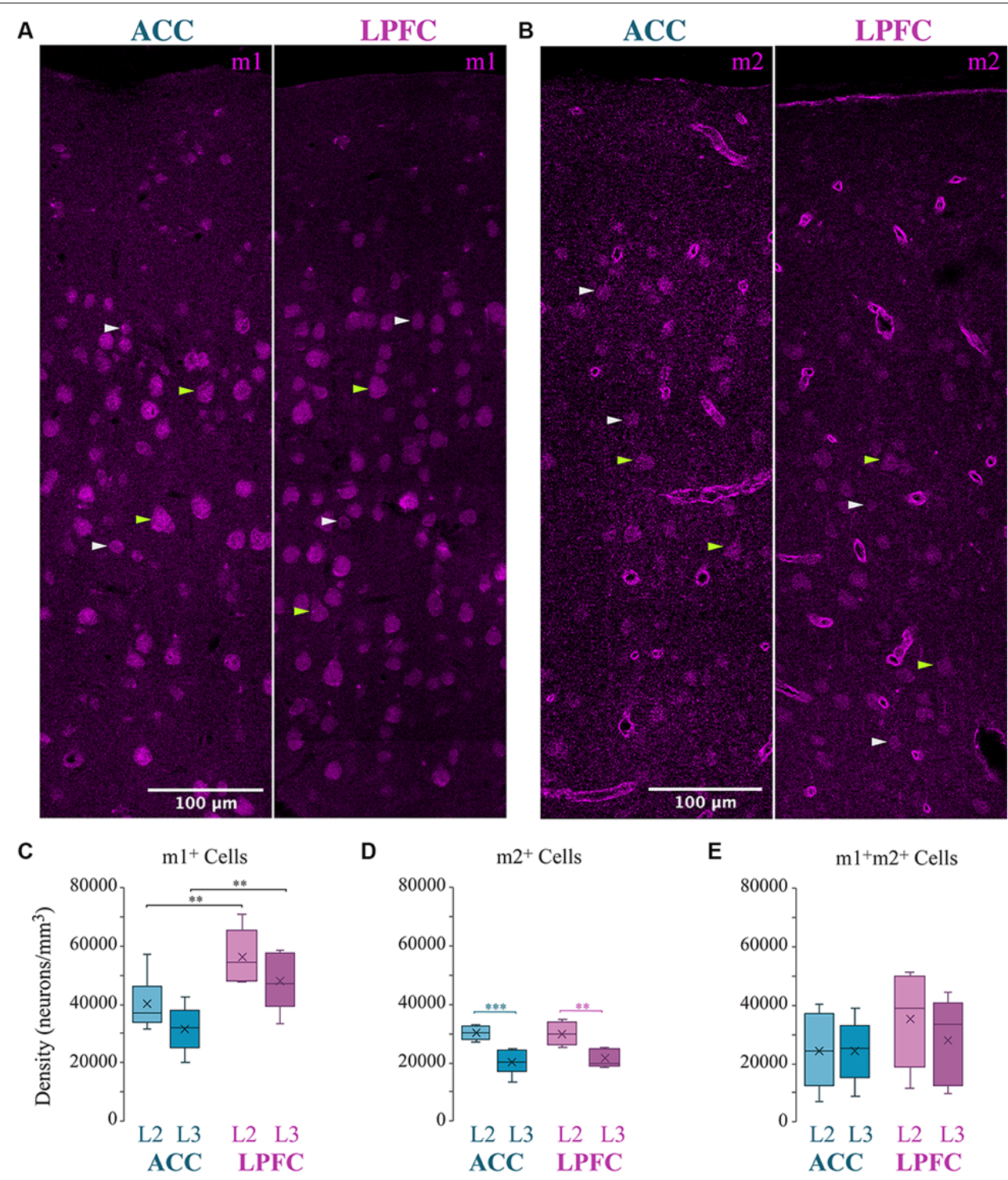

D

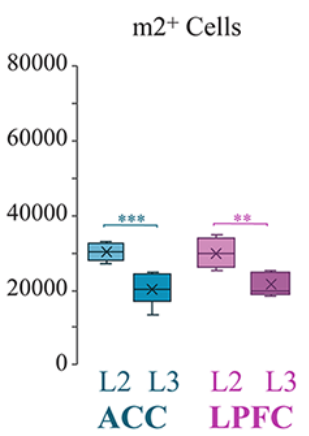

E

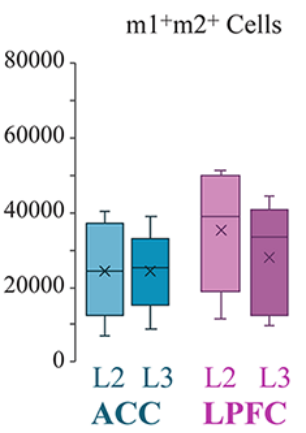

$\mathbf{F}$

L2

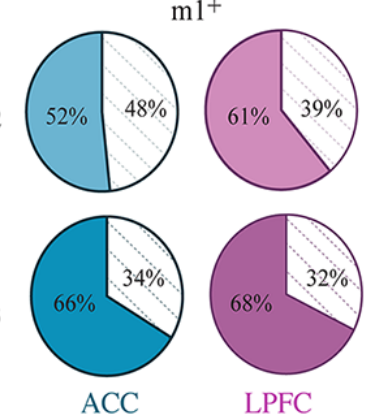

G

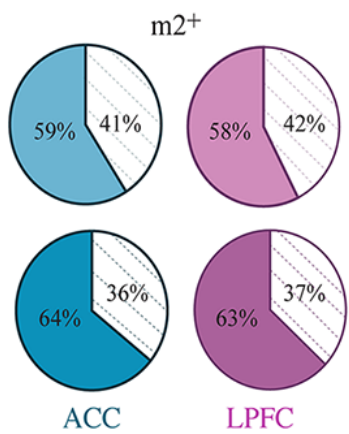

H

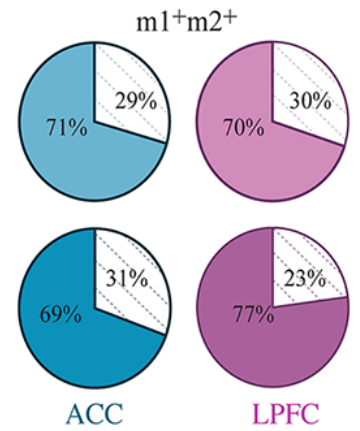

$\%$ pyramidal $Q \%$ non-pyramidal

FIGURE 1 | Distribution of $\mathrm{m}^{+}$and $\mathrm{m} 2^{+}$expressing cells in the ACC and LPFC. (A,B) Representative confocal image of $\mathrm{L} 1$-L3 showing $\mathrm{m} 1^{+}$(A) or $\mathrm{m} 2^{+}$(B) cells in ACC and LPFC. Green arrows indicate morphologically identified pyramidal neurons, white arrows are non-pyramidal cells. Scale bar $=100 \mu \mathrm{m}$. (C-E) Box and whisker density plots of $\mathrm{m}^{+}{ }^{+}$(C), $\mathrm{m} 2^{+}$(D), or (E) $\mathrm{m}^{+} \mathrm{m}^{+}$expressing cells per $\mathrm{mm}^{3}$ in $\mathrm{L} 2$ and $\mathrm{L} 3$ of ACC and LPFC. (F-H) The relative proportion of $\mathrm{m} 1^{+}(\mathbf{F})$ or $\mathrm{m} 2^{+}$ (G) or $\mathrm{m}^{+} \mathrm{m}^{+} \mathbf{( H )}$ pyramidal vs. non-pyramidal cells in $\mathrm{L} 2$ (top) and L3 (bottom) in the ACC and LPFC were equivalent between areas and layers. ${ }^{* *} p \leq 0.01$, ${ }^{* * *} p \leq 0.001$. LPFC, lateral prefrontal cortex; ACC, anterior cingulate cortex. 
the density of morphologically identified $\mathrm{MAP}^{+}$pyramidal neurons co-expressing either $\mathrm{m} 1^{+}, \mathrm{m}^{+}$, or $\mathrm{m}^{+} \mathrm{m} 2^{+}$receptors (Figure 2). Within-area comparisons showed the total densities of $\mathrm{MAP}^{+}$pyramidal neurons in L2 and L3 were equivalent (Figure 2B). However, between-area comparisons showed that LPFC had a greater density of L2 and L3 $\mathrm{MAP2}^{+}$pyramidal neurons compared to ACC (Two-Way ANOVA layer $\times$ area, Fisher's LSD post hoc: LPFC vs. ACC L2: $p=0.021$; LPFC vs. ACC L3: $p=0.003$; Figure 2B). Further, in L2, LPFC had a significantly greater density of the subpopulation of $\mathrm{MAP}^{+} \mathrm{m}^{+}$pyramidal neurons, compared to ACC $(p=0.018$, Figure 2C). There were no significant differences in the density of other $\mathrm{MAP}^{+}$pyramidal neuron subpopulations: $\mathrm{MAP}^{+} \mathrm{m}^{+}$ (Figure 2D), $\mathrm{MAP}^{+} \mathrm{m}^{+} \mathrm{m}^{+}$(Figure 2E), or MAP2 ${ }^{+} \mathrm{m} 1^{-} \mathrm{m} 2^{-}$ neurons (Figure $2 \mathrm{~F}$ ). An assessment of the proportion of these $\mathrm{MAP}^{+}$pyramidal subpopulations (Figures $2 \mathrm{G}, \mathbf{H}$ ) showed that the majority of $\mathrm{MAP2}^{+}$pyramidal neurons expressed $\mathrm{ml}^{+}$ and/or $\mathrm{m} 2^{+}$receptors $(72-80 \%)$, and the proportions did not differ between ACC and LPFC. About $38-46 \%$ of $\mathrm{MAP}^{+}$ pyramidal neurons co-expressed both $\mathrm{m}^{+}$and $\mathrm{m} 2^{+}$and $24-36 \%$ expressed $\mathrm{ml}^{+}$alone, which was greater than the proportion of $\mathrm{MAP}^{+}$pyramidal neurons that expressed $\mathrm{m}^{+}$alone $\sim 2 \%$ (Figures 2G,H).

\section{Differential Distribution of $\mathrm{m}^{+}$and $\mathrm{m}^{+}$ Expressing SMI- $32^{+}$and $\mathrm{CB}^{+}$Pyramidal Neuron Subpopulations in ACC and LPFC}

We next characterized $\mathrm{m}^{+}$and $\mathrm{m}^{+}$expression on specific subclasses of pyramidal neurons expressing the neurofilament protein $\mathrm{SMI}_{-} 32^{+}$as well as the calcium-binding protein, calbindin $\left(\mathrm{CB}^{+}\right)$. SMI-32 has been shown to be strongly expressed in long-range projecting pyramidal neurons in L3 and L5, such as corticospinal neurons (Campbell and Morrison, 1989; Barbas and Garcia-Cabezas, 2016). CB, although mainly a marker for inhibitory interneurons in the monkey cortex, also lightly labels a small population of pyramidal neurons in limbic areas (Hof and Nimchinsky, 1992; DeFelipe, 1997; Kondo et al., 1999; Dombrowski et al., 2001).

Similar to $\mathrm{MAP}^{+}$, the subpopulation of SMI- $32^{+}$pyramidal neurons was present in a greater density in LPFC than in ACC (Two-Way ANOVA layer $\times$ area, Fisher's LSD post hoc; LPFC vs. ACC: L2 $p=0.04$, L3 $p=2.59 \times 10^{-5}$; Figures $\left.3 \mathrm{~A}-\mathrm{E}\right)$, as shown in previous studies (Hof and Nimchinsky, 1992; Barbas and Garcia-Cabezas, 2016). In both ACC and LPFC, $\sim 100 \%$ of the total SMI- $32^{+}$neurons expressed $\mathrm{ml}^{+}$, while $81-100 \%$ of all SMI- $32^{+}$neurons expressed $\mathrm{m} 2^{+}$(not shown). Within-area laminar comparisons showed that the density and proportion of SMI- $32^{+}$neurons expressing $\mathrm{m}^{+}$or $\mathrm{m}^{+}$was greater in LPFC L3 compared to L2 (LPFC L2 vs. L3: SMI32 ${ }^{+} \mathrm{ml}^{+}$: $p=6.30 \times 10^{-10} ; \mathrm{SMI}^{+} 2^{+} 2^{+}: p=2.27 \times 10^{-4}$, Fisher's LSD post hoc; $p=5.03 \times 10^{-8}$, Chi-Square and Bonferroni post hoc; Figures 3F,G). However, within the ACC, there was no statistical difference between the layers. Between-area comparisons showed that there was a significantly greater density of total SMI-32 ${ }^{+}$ and SMI- $32^{+} \mathrm{m}^{+}$neurons in L3 of LPFC than in ACC (LPFC vs. ACC, Fisher's LSD post hoc: SMI- $32^{+} p=2.59 \times 10^{-5}$, SMI-
$32^{+} \mathrm{m} 1^{+} p=2.80 \times 10^{-11}$; Figure 3F). SMI- $32^{+} \mathrm{m} 2^{+}$neuron densities exhibited between-area differences in both layers, with LPFC having significantly greater densities compared to ACC (LPFC vs. ACC, L2: $p=0.01$; $3: p=5.15 \times 10^{-7}$; Figure 2G). Further, we observed a significantly greater proportion of SMI$32^{+} \mathrm{m}^{+}$in LPFC L3 compared to ACC (LPFC vs. ACC L3: $p=3.18 \times 10^{-7}$, Chi-Square and Bonferroni post hoc).

In contrast to the predominance of $\mathrm{SMI}-32^{+} \mathrm{ml}^{+}$or $\mathrm{m}^{+}$neurons in LPFC, the subset of pyramidal neurons co-expressing SMI- $32^{+}$and $\mathrm{CB}^{+}$were present in greater density in ACC. Specifically, between-area comparison showed that $\mathrm{SMI}-32^{+} \mathrm{CB}^{+} \mathrm{m}^{+}$and $\mathrm{SMI}-32^{+} \mathrm{CB}^{+} \mathrm{m} 2^{+}$neurons in $\mathrm{L} 3$ had a significantly greater density in ACC compared to LPFC (LPFC vs. ACC L3, $1^{+}: p=0.02 ; \mathrm{m}^{+}: p=0.03$, Fisher's LSD post hoc; Figures $3 \mathrm{H}, \mathrm{I}$ ). Similarly, the proportions of $\mathrm{SMI}-32^{+} \mathrm{CB}^{+}$ expressing $\mathrm{m}^{+}$and $\mathrm{m}^{+}$neurons were significantly greater in L3 ACC than in LPFC: with $\sim 65 \%$ in ACC compared to $\sim 16 \%$ in LPFC expressing $\mathrm{m}^{+}\left(p=3.22 \times 10^{-2}\right.$, Chi-Square and Bonferroni post hoc), and $\sim 74 \%$ in ACC compared to $\sim 21 \%$ in LPFC expressing $\mathrm{m}^{+}\left(p=3.57 \times 10^{-2}\right.$; data not shown $)$.

In summary, $\mathrm{ml}^{+}$pyramidal neurons were greater in density than $\mathrm{m} 2^{+}$pyramidal neurons. Interestingly, the subset of SMI$32^{+}$and $\mathrm{SMI}-32^{+} \mathrm{CB}^{+}$pyramidal neurons expressing $\mathrm{m} 1^{+} / \mathrm{m}^{+}$ exhibited opposite regional distributions: $\mathrm{SMI}_{-} 32^{+} \mathrm{m} 1^{+} / \mathrm{m}^{+}$ neurons were greater in LPFC than ACC, while SMI$32^{+} \mathrm{CB}^{+} \mathrm{m} 1^{+} / \mathrm{m}^{+}$neurons were greater in ACC than in LPFC (Figures 3E-I).

\section{Specificity of $\mathrm{m}^{+}$and $\mathrm{m} 2^{+}$Cholinergic Receptor Expression on GABAergic Interneuron Subtypes}

Previous studies have shown that different neurochemical classes of inhibitory neurons in rhesus monkeys expressing the calciumbinding proteins calbindin $\left(\mathrm{CB}^{+}\right)$, parvalbumin $\left(\mathrm{PV}^{+}\right)$, and calretinin $\left(\mathrm{CR}^{+}\right)$differ in density and laminar distribution across prefrontal cortices (Dombrowski et al., 2001). Here, we assessed the density of the specific interneuron subpopulations that expressed $\mathrm{m} 1$ or $\mathrm{m} 2 \mathrm{mAChR}$ subtypes (Figures 4, 5).

Consistent with previous work on the total density of $\mathrm{PV}^{+}$ interneurons (Dombrowski et al., 2001), we observed that $\mathrm{PV}^{+} \mathrm{m} 1^{+}$and $\mathrm{PV}^{+} \mathrm{m} 2^{+}$subpopulations showed a significantly greater density in LPFC compared to ACC $\left(\mathrm{ml}^{+} \mathrm{L} 2: p=0.04\right.$, L3: $p=8.3 \times 10^{-6}, \mathrm{~m} 2^{+} \mathrm{L} 2 p=0.03 ; p=2.7 \times 10^{-4}$; Two-Way ANOVA for each area and marker, Fisher's LSD post hoc; Figures 4, 5A,D). Further, within LPFC, a laminar difference was observed, with the density of both $\mathrm{PV}^{+} \mathrm{ml}^{+}$ $\left(p=2.02 \times 10^{-4}\right.$, Figure 5A $)$ and $\mathrm{PV}^{+} \mathrm{m} 2^{+}\left(p=3.42 \times 10^{-3}\right.$, Figure 5D) interneurons being greater in L3 compared to L2.

For the non-pyramidal $\mathrm{CB}^{+}$interneurons, the density of $\mathrm{m}^{+}$and $\mathrm{m}^{+}$expressing subpopulations significantly differed between layers, but not between areas (Figures 4, 5B,E). Between-layer comparisons within each area showed that $\mathrm{L} 2 \mathrm{had}$ a significantly greater density of $\mathrm{CB}^{+} \mathrm{ml}^{+}$and $\mathrm{CB}^{+} \mathrm{m}^{+}$ interneurons compared to L3 (ACC: $\mathrm{ml}^{+} p=1.13 \times 10^{-5}$, $\mathrm{m} 2^{+} p=8.89 \times 10^{-3}$; LPFC: $\mathrm{m}^{+} p=1.24 \times 10^{-4}, \mathrm{~m}^{+}$ $p=6.68 \times 10^{-3}$; Figures 5B,E). Furthermore, within ACC L2, 


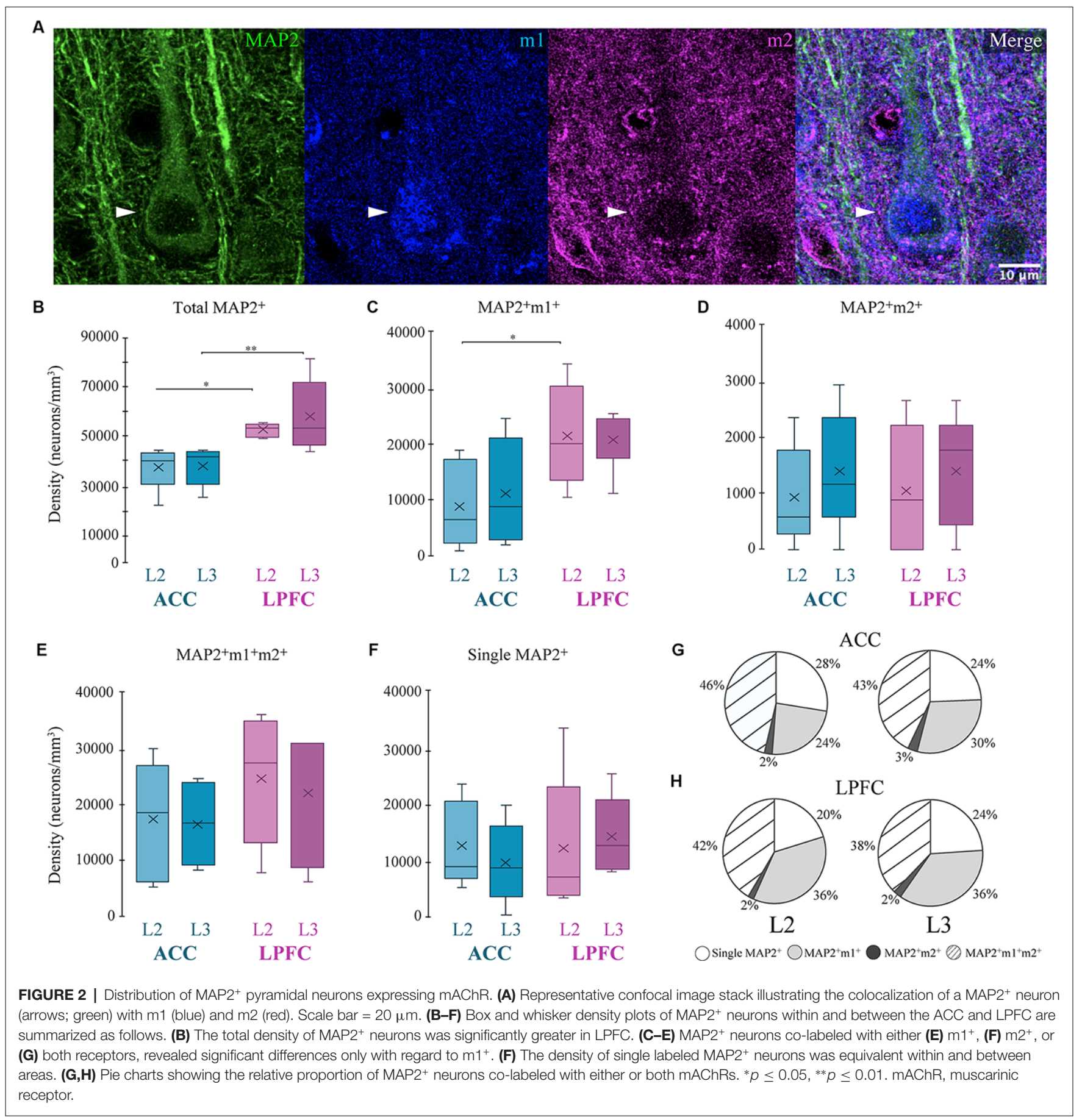

a greater density of $\mathrm{CB}^{+}$interneurons colocalized with $\mathrm{m}^{+}$than $\mathrm{m}^{+}\left(\mathrm{CB}^{+} \mathrm{m} 1^{+}\right.$vs. $\mathrm{CB}^{+} \mathrm{m} 2^{+}: p=0.007$; Figures 5B,E).

The density of $\mathrm{m}^{+}$and $\mathrm{m}^{+}$expressing $\mathrm{CR}^{+}$interneurons showed significant between-layer and between-area differences (Figures 4, 5C,F). Within the ACC, the density of $\mathrm{CR}^{+} \mathrm{ml}^{+}$ $\left(p=9.09 \times 10^{-4}\right)$ and $\mathrm{CR}^{+} \mathrm{m} 2^{+}\left(p=9.86 \times 10^{-5}\right)$ interneurons was significantly greater in L2 compared to L3 (Figures $\mathbf{5 C , F}$ ). However, the LPFC had a significant laminar difference only for $\mathrm{CR}^{+} \mathrm{m} 2^{+}$interneurons (L2 vs. L3 $p=0.03$; Figure $5 \mathrm{~F}$ ). Between-area comparisons showed that in L2, ACC had a greater mean density of $\mathrm{CR}^{+} \mathrm{m} 2^{+}$interneurons compared to the LPFC $(p=0.04$, Figure 5F).

We compared the relative proportion of $\mathrm{m}^{+}$and $\mathrm{m}^{+}$ expressing interneurons within each interneuron subtype. Similar to pyramidal neurons, the majority of inhibitory neurons expressed mAChRs, with the proportion expressing $\mathrm{m}^{+}$greater than those expressing $\mathrm{m} 2^{+}$(Figures 5G-I). The proportion of $\mathrm{m}^{+}$expressing subpopulations did not differ across neurochemical interneuron types or between cortical areas $(100 \%$ of all PV; $95-100 \%$ of all CB and $92-99 \%$ 


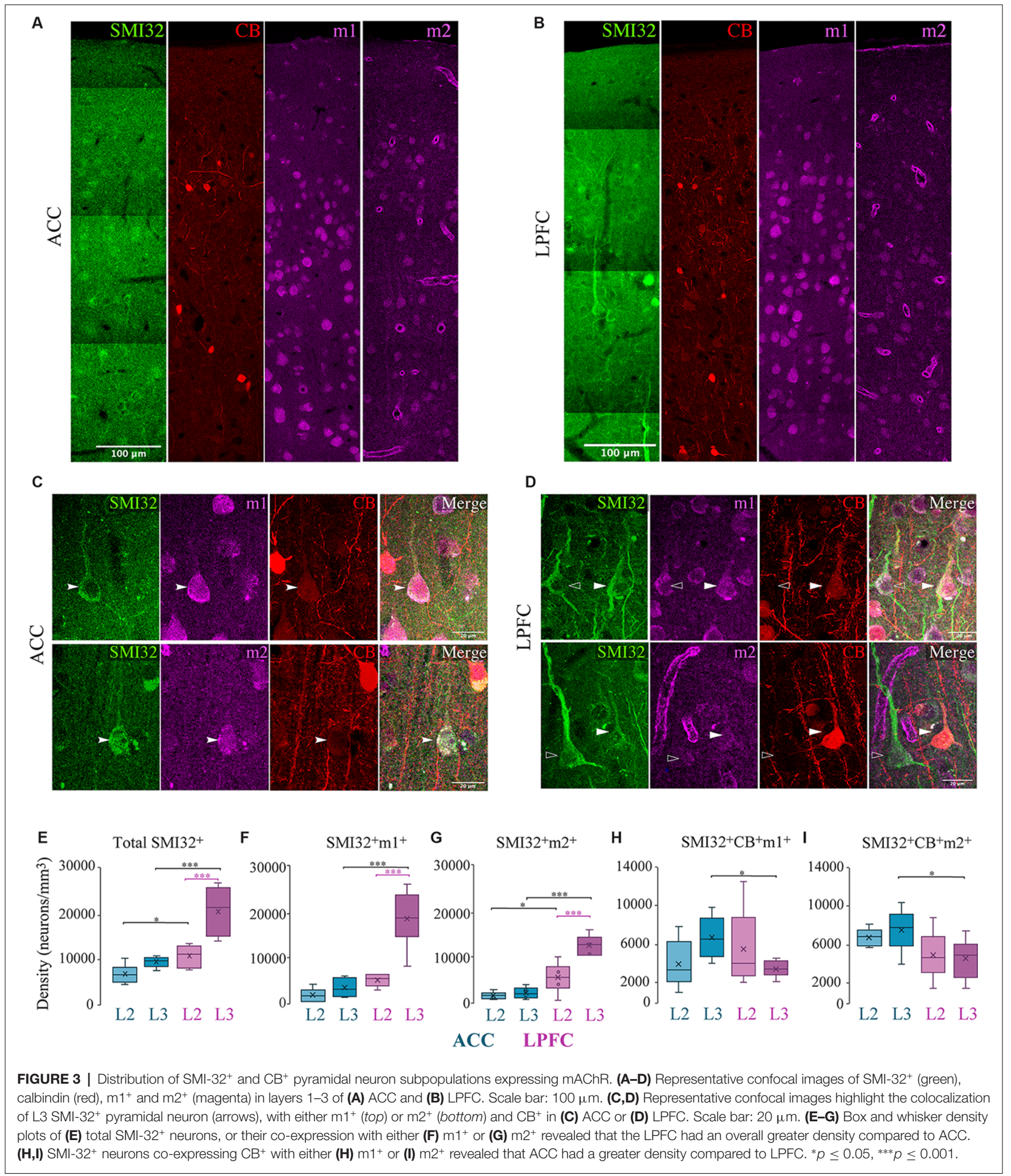

of all CR). However, the ACC and LPFC differed in the proportion of $\mathrm{m}^{+}$expressing subpopulations depending on the interneuron subclass and layer. In the ACC, $100 \%$ of $\mathrm{PV}^{+}$ interneurons express $\mathrm{m}^{+}$(presumably colocalized with $\mathrm{m}^{+}$) while in the LPFC, $84 \%$ of $\mathrm{PV}^{+}$interneurons in $\mathrm{L} 2$ and $71 \%$ in L3 expressed $\mathrm{m}^{+}$, in proportions significantly less than ACC (L2: $p=1.59 \times 10^{-5}$, L3: $p=3.45 \times 10^{-10}$, Fisher Exact Test; Figure 5G). Similar to PV, between-area comparison revealed 

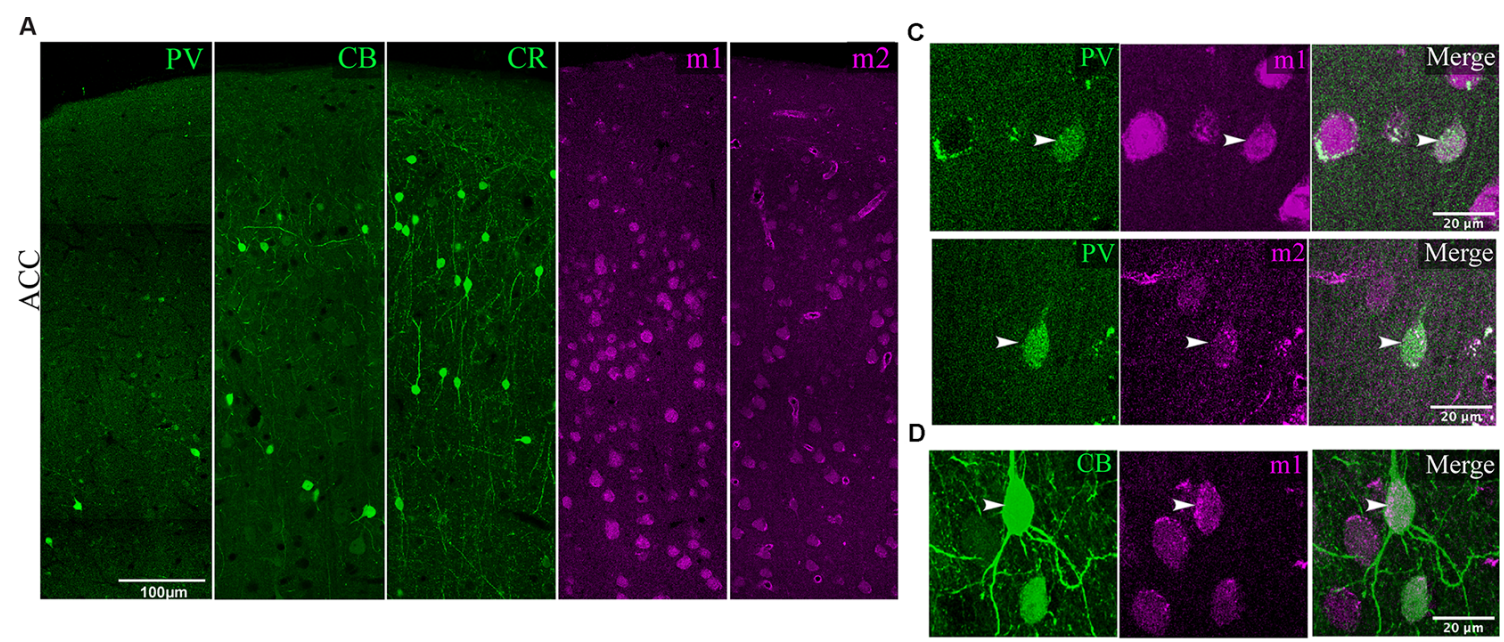

B
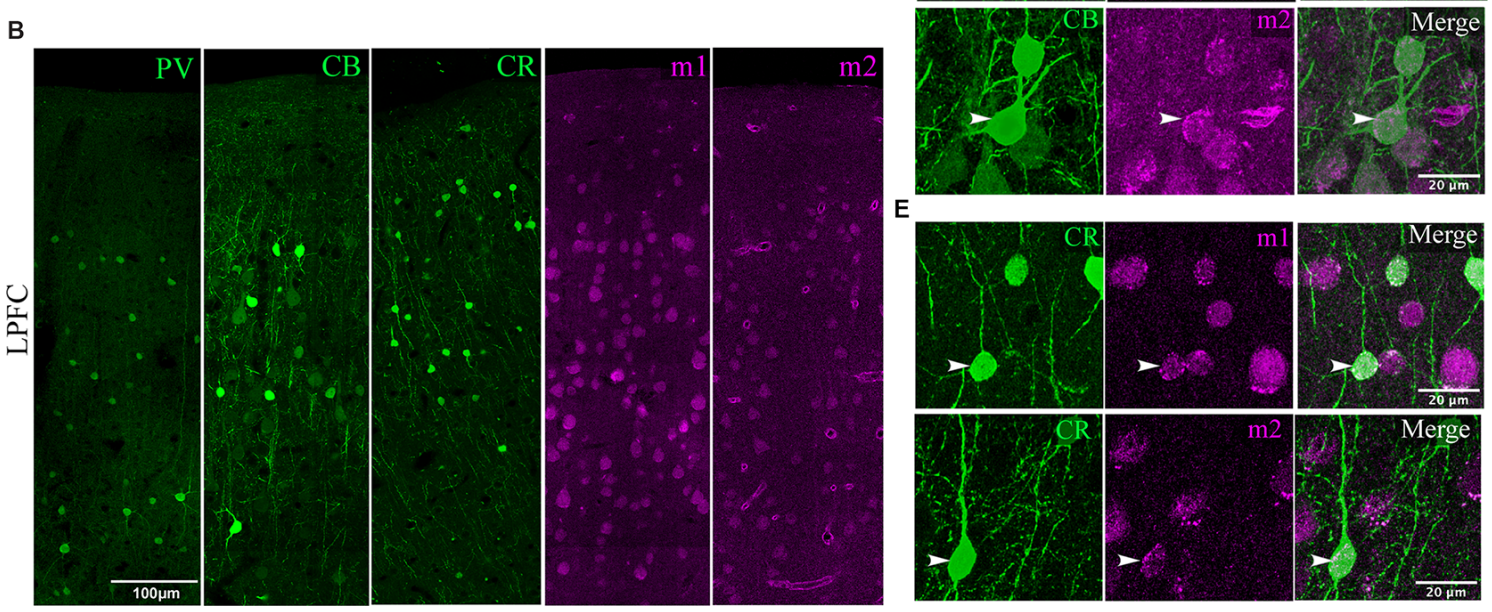

FIGURE 4 | Visualization of mAChR on distinct inhibitory neurons. (A,B) Low magnification confocal image stacks of coronal sections in layers 1-3 of (A) ACC and (B) LPFC showing the distribution of inhibitory subtypes (green) $\mathrm{PV}^{+}, \mathrm{CB}^{+}, \mathrm{CR}^{+}$, and muscarinic receptors (magenta) $\mathrm{m} 1^{+}$and $\mathrm{m} 2^{+}$. Scale bar: $100 \mu \mathrm{m}$. (C-E) Representative high magnification confocal images of inhibitory neurons (arrows) labeled (C) $\mathrm{PV}^{+}$, (D) $\mathrm{CB}^{+}$, and (E) $\mathrm{CR}^{+}$that co-express either $\mathrm{m} 1^{+}$(top) or $\mathrm{m} 2^{+}$ (bottom) receptors. Scale bar: $20 \mu \mathrm{m}$.

a significantly higher proportion of $\mathrm{CB}^{+} \mathrm{m} 2^{+}$interneurons in L2 (81\% in ACC; $61 \%$ in LPFC) and L3 (87\% in ACC; $56 \%$ in LPFC) of ACC than in LPFC (L2 $p=1.67 \times 10^{-3}$, L3 $p=8.17 \times 10^{-7}$, Fisher's LSD post hoc; Figure $\left.5 \mathbf{H}\right)$. A significantly higher proportion of $\mathrm{CR}^{+} \mathrm{m} 2^{+}$interneurons was also found in ACC than in LPFC (L2: $3.77 \times 10^{-3}$, L3: $\left.1.1 \times 10^{-5}\right)$. In the ACC, the proportion of $\mathrm{CR}^{+} \mathrm{m} 2^{+}$accounted for $92 \%$ of $\mathrm{L} 2$ and $87 \% \mathrm{~L} 3$ of the total $\mathrm{CR}^{+}$interneurons (Figure 5I), similar to the proportion found in $\mathrm{m}^{+}$expressing $\mathrm{CR}^{+}$interneurons. In the LPFC, $\mathrm{CR}^{+} \mathrm{m}^{+}$interneurons (73\% of all $\mathrm{CR}^{+}$in $\mathrm{L} 2$ and $63 \%$ in $\mathrm{L} 3$ ) represented a lower proportion of the total $\mathrm{CR}^{+}$population than the $\mathrm{CR}^{+} \mathrm{ml}^{+}$interneurons $\left(99 \%\right.$ of all $\mathrm{CR}^{+}$in $\mathrm{L} 2,88 \%$ in $\mathrm{L} 3$; Figure 5I).

\section{Subcellular Localization of mAChR Along MAP2 ${ }^{+}$Pyramidal Neurons}

Cholinergic modulation of cortical circuits is dependent on the location of mAChRs on different morphological compartments of neurons outside of the soma (Mrzljak et al., 1993; Disney et al., 2006). Thus, we examined the optical density of $\mathrm{m}^{+}$or $\mathrm{m} 2^{+}$receptor expression within the neuropil (containing neurites and synapses) of L1-L3 in both LPFC and ACC, quantified as the percent area labeled within total tissue volume examined (Figures 6A-C,F). Within area, the percent area of $\mathrm{ml}^{+}$was significantly greater in ACC L3 than in L1 ( $p=0.03$, Two-Way ANOVA area $x$ layer, Fisher's LSD post hoc), but in LPFC was significantly greater in L1 than in L2 $\left(p=7.5 \times 10^{-3}\right.$; Figure 6C). Further, a between-area comparison revealed a significantly greater density of $\mathrm{ml}^{+}$in L1 of the LPFC compared to ACC $\left(p=1.7 \times 10^{-4}\right.$; Figure 6C). The percent area labeled with $\mathrm{m} 2^{+}$was equivalent across areas and layers of ACC and LPFC (Figure 6F).

We then examined the percent area of colocalization of $\mathrm{MAP2}^{+}$with either $\mathrm{m}^{+}$or $\mathrm{m}^{+}$within the total tissue volume in L1, L2, and L3 of ACC and LPFC (Figures 6A,B). Within-area comparisons found a significantly greater percent area of $\mathrm{MAP}^{+}$colocalized with $\mathrm{m}^{+}$in ACC L2 than in L1 ( $p=0.02$, main effect layer, Fisher LSD post hoc) and in LPFC 


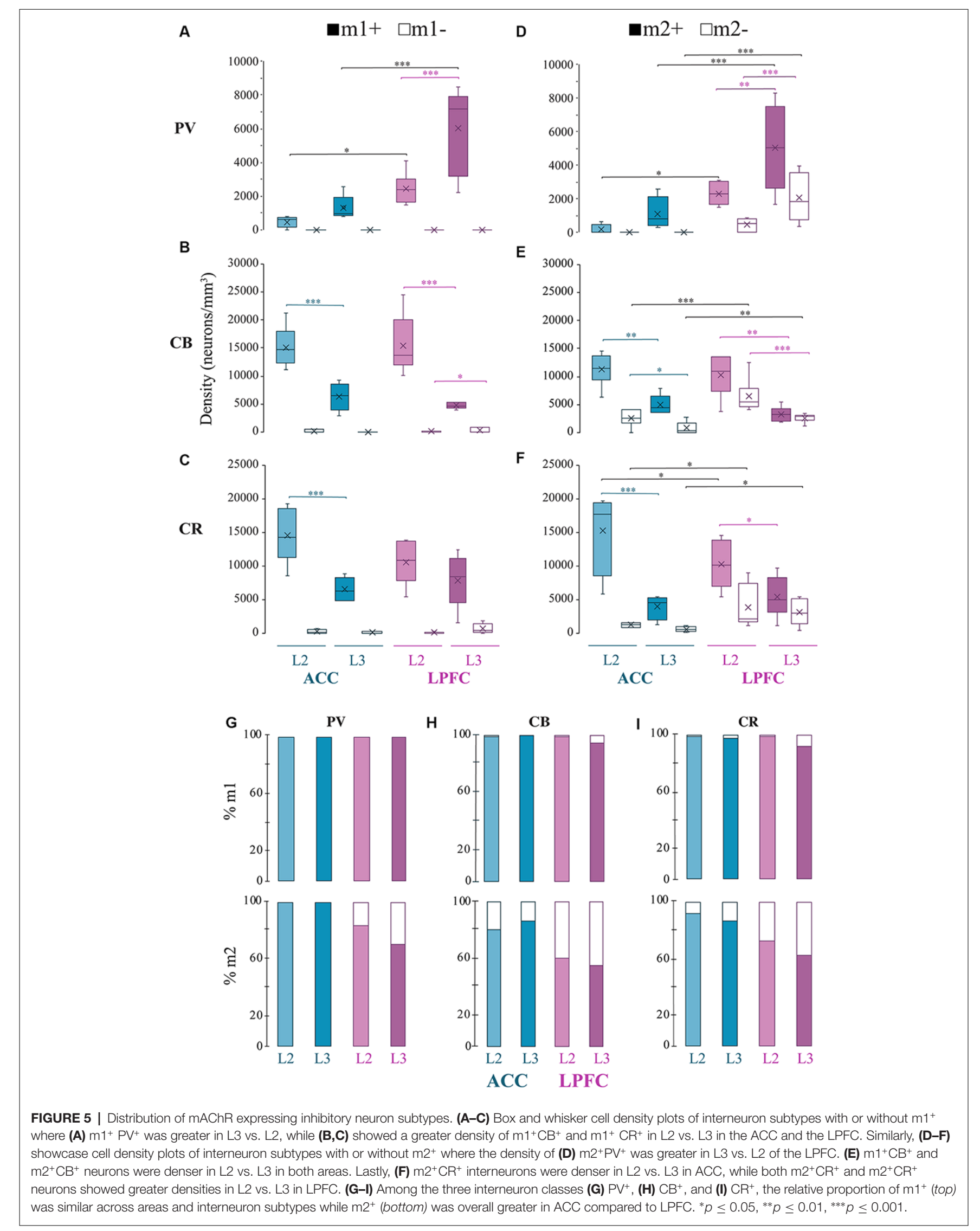



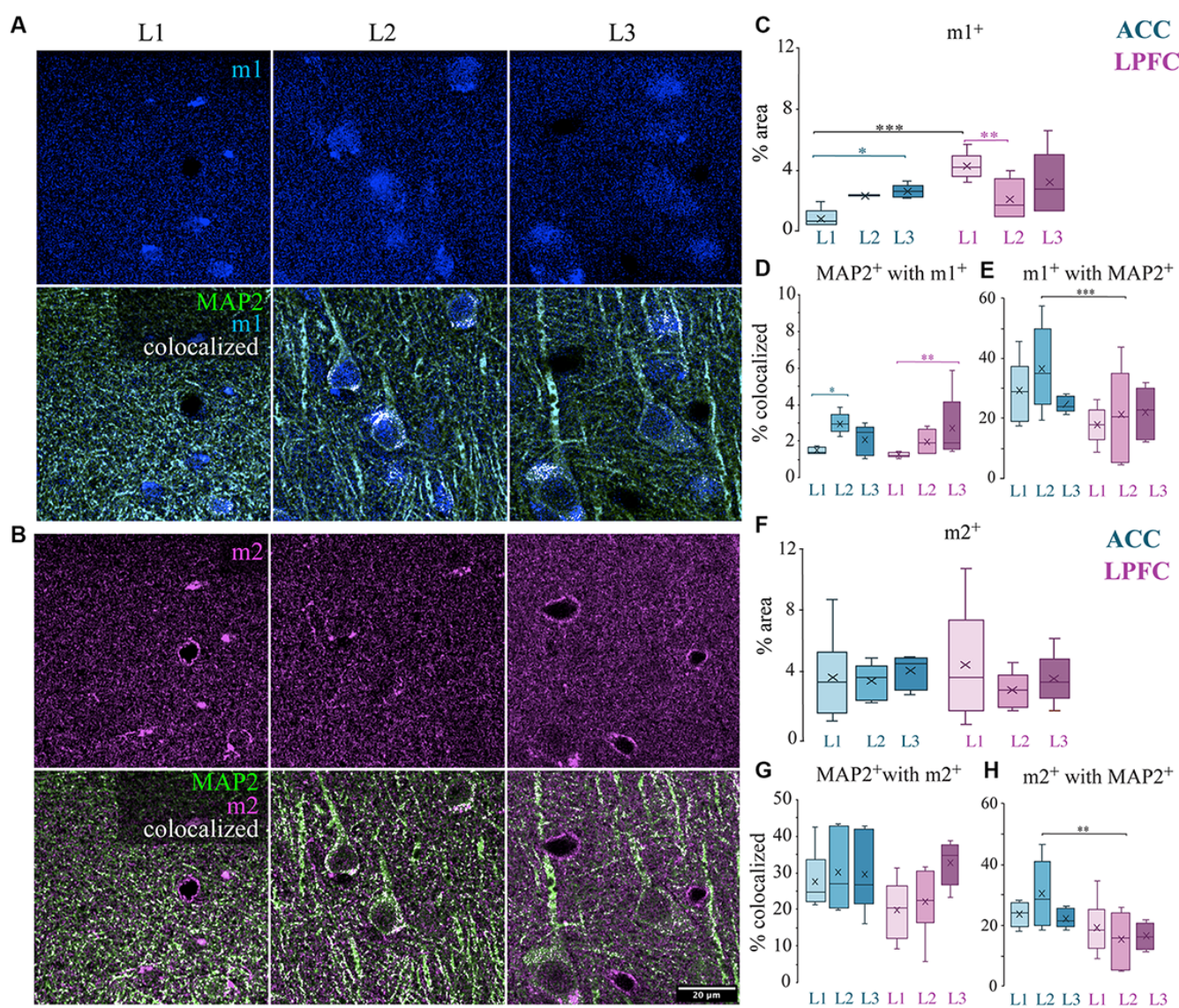

G $\mathrm{MAP2}^{+}$with $\mathrm{m}^{+} \quad \mathrm{H} \quad \mathrm{m}^{+}$with $\mathrm{MAP2}^{+}$
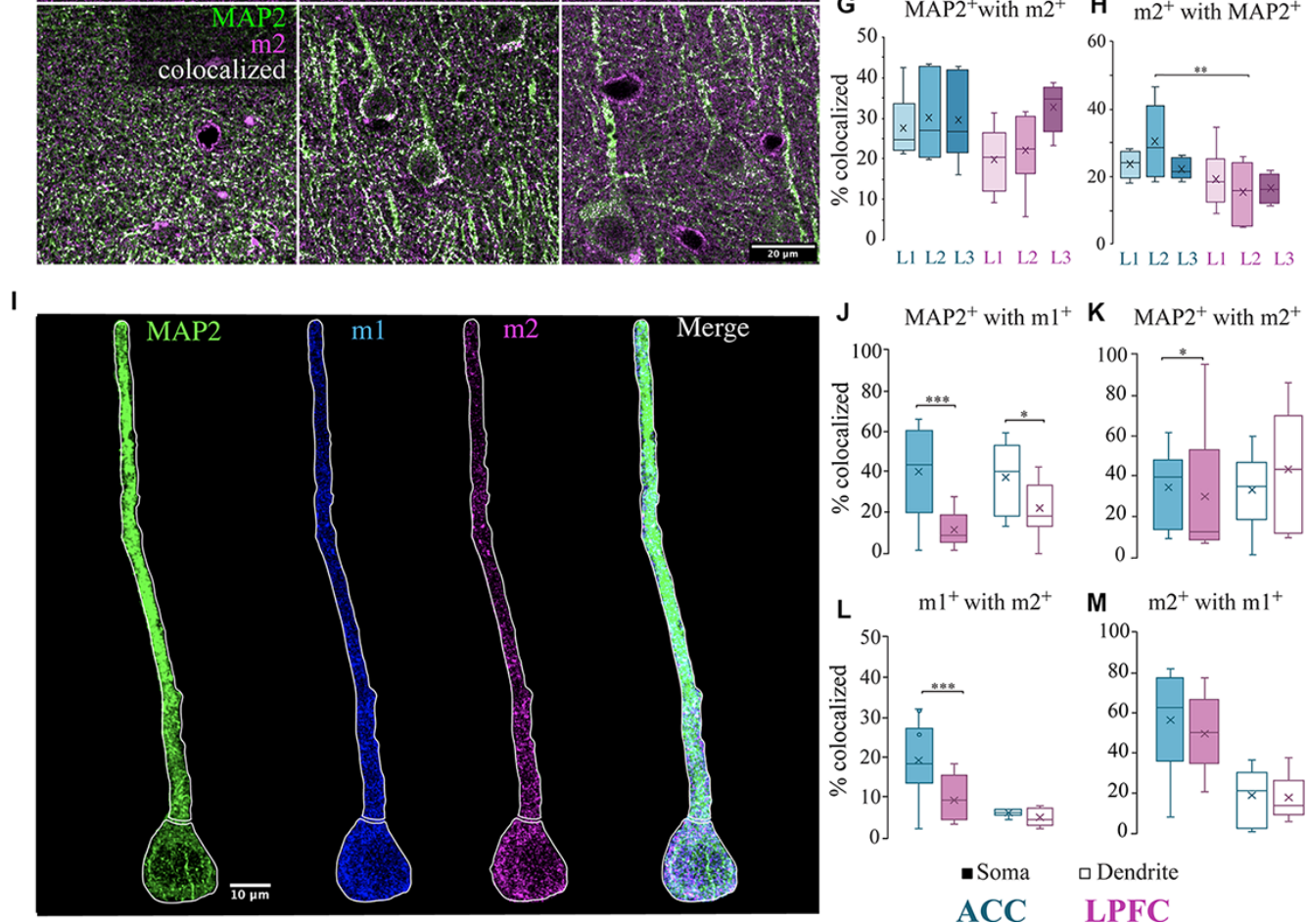

FIGURE 6 | Localization of mAChR on MAP2+ pyramidal neurons. (A,B) Representative confocal images of the distribution in the L1-L3 neuropil of either $(\mathbf{A}) \mathrm{m}^{+}$ receptors (blue) (top) and $\mathrm{MAP}^{+}$(green) $\mathrm{m}^{+}$(blue) with colocalized pixels (white) (bottom) or (B) $\mathrm{m}^{+}$receptors (magenta) (top) and $\mathrm{MAP}^{+}$(green) $\mathrm{m} 2^{+}$(magenta) with colocalized pixels (white) (bottom). Scale bar: $20 \mu \mathrm{m}$. (C) Box and whisker plots showing density (\% area) of $\mathrm{m} 1^{+}$label and (D) colocalization coefficients representing \% of MAP2 ${ }^{+}$with $\mathrm{m}^{+}$and (E) \% of $\mathrm{m}^{+}{ }^{+}$with MAP2. In ACC, L2 had a significantly greater percent of MAP2 ${ }^{+}$with $\mathrm{m} 1^{+}$compared to $\mathrm{L} 1$ while $\mathrm{LPFC}$ had a significantly greater percent in L3 compared to L1 (D). ACC L2 had a significantly greater percent of $m 1^{+}$colocalized with MAP2 ${ }^{+}$than LPFC (E). (F) Box and whisker plots showing density (\% area) of $\mathrm{m} 2^{+}$label and (G) colocalization coefficients representing $\%$ of $\mathrm{MAP}^{+}$with $\mathrm{m} 2^{+}$and $(\mathbf{H}) \%$ of $\mathrm{m} 2^{+}$with $\mathrm{MAP} 2$. ACC $\mathrm{L} 2$ had a significantly greater percent of $\mathrm{m}^{+}$colocalized with $\mathrm{MAP2}^{+}$than $\mathrm{LPFC}$ (H). (I) Representative confocal images showing proximal apical dendritic and somatic ROls illustrated by white outline of representative MAP2 ${ }^{+}$neuron (green) co-labeled with $\mathrm{m}^{+}{ }^{+}$(blue) and $\mathrm{m} 2^{+}$(magenta). Scale bar: $10 \mu \mathrm{m}$. (K-M) Box and whisker plots of percent area of $\mathrm{m} 1$ and $\mathrm{m} 2$ in the somatic (filled) or dendritic (unfilled) ROls of individual cells. (J-K) The colocalized \% of MAP2 ${ }^{+}$with either (J) $\mathrm{m}^{+}{ }^{+}$ or (K) $\mathrm{m}^{+}$was significantly greater in the ACC somatic compartment, but only (J) MAP2 ${ }^{+} \mathrm{m}^{+}$was greater in the dendritic compartment of the ACC compared to the LPFC. (L,M) The colocalized \% of (L) $\mathrm{m} 1^{+}$with $\mathrm{m} 2^{+}$or (M) $\mathrm{m} 2^{+}$with $\mathrm{m} 1^{+} .{ }^{*} p \leq 0.05,{ }^{* *} p \leq 0.01,{ }^{* * *} p \leq 0.001$. 
L3 than in L1 $\left(p=9.41 \times 10^{-3}\right.$; Figure 6D); however, there were no between-area differences. There were no significant within- or between-area differences in the percent area of $\mathrm{MAP}^{+}$colocalized with $\mathrm{m} 2^{+}$(Figure 6G). However, among the total $\mathrm{m}^{+}$or $\mathrm{m}^{+}$label in the neuropil, a greater percent was colocalized with $\mathrm{MAP}^{+}$in ACC L2 compared to LPFC (Figures 6E,H). These data suggest that among all structures bearing $\mathrm{m}^{+}$and $\mathrm{m}^{+}$receptors in $\mathrm{L} 2, \mathrm{MAP}^{+}$dendrites represent a larger proportion of the potential ACh modulatory target in ACC than in LPFC.

The data in the neuropil suggested differential subcellular localization of $\mathrm{m} 1$ and $\mathrm{m} 2$ receptors within ACC and LPFC. Thus, we further investigated the specific localization and density of $\mathrm{m}^{+}$and $\mathrm{m}^{+}$on distinct subcellular compartments of individual neurons. We performed a segmentation of the proximal apical dendrite and soma of individual L3 $\mathrm{MAP}^{+}$ pyramidal neurons (Figure 6I). We then quantified the density ( $\%$ area) of colocalized label within segmented $\mathrm{MAP}^{+}$ subcellular ROIs and assessed overlap of label as follows: (1) $\mathrm{MAP}^{+} \mathrm{m}^{+}$, (2) $\mathrm{MAP2}^{+} \mathrm{m} 1^{+}$, and (3) $\mathrm{MAP}^{+} \mathrm{m}^{+} \mathrm{m}^{+}$in the ACC ( $n=10$ soma/dendrite) and LPFC ( $n=10$ soma/dendrite). Compared to the LPFC, the ACC had a greater density of $\mathrm{m}^{+}$label within $\mathrm{MAP}^{+}$somatic and dendritic ROIs (somatic: $p=8.87 \times 10^{-6}$, dendritic: $p=1.52 \times 10^{-3}$; One-Way ANOVA; Figure 6J), while $\mathrm{m}^{+}$within MAP2 ${ }^{+}$was only significant in the somatic ROI ( $p=2.31 \times 10^{-4}$; One-Way ANOVA; Figure 6K). Within-area comparisons between the two compartments (soma vs. dendrite) showed an equivalent $\mathrm{m}^{+} / \mathrm{m} 1^{+}$and $\mathrm{m}^{+} / \mathrm{m} 2^{+}$colocalization (Figures $6 \mathbf{L}, \mathbf{M}$ ). However, between-area comparisons showed that post-synaptic $\mathrm{m}^{+}$receptor had a significantly higher percentage of colocalization with presynaptic $\mathrm{m}^{+}$specifically in the somatic compartment of ACC $\mathrm{MAP}^{+}$ pyramidal neurons compared to $\operatorname{LPFC}\left(p=4.49 \times 10^{-4}\right)$ (Figure 6L). Although we found that there was a greater cell density of $\mathrm{MAP}^{+}$pyramidal neurons in the LPFC (Figure 2D), the $\mathrm{m}^{+}$and $\mathrm{m} 2^{+}$receptor expression density per individual $\mathrm{MAP}^{+}$neuron was greater in ACC than LPFC.

\section{Presynaptic Location of $\mathrm{m}^{+}{ }^{+}$on Excitatory and Inhibitory Axon Terminals}

Although a small subset of $\mathrm{m} 1$ receptors can also be located presynaptically, evidence has shown that most of the presynaptic action of $\mathrm{ACh}$ is mediated by $\mathrm{m} 2$ receptors (Sarter et al., 2009; Colangelo et al., 2019). The $\mathrm{m} 2^{+}$muscarinic subtype is the predominant receptor found on presynaptic glutamatergic and GABAergic axon terminals (Sarter et al., 2009; Colangelo et al., 2019), where they act to suppress neurotransmitter release (Mrzljak et al., 1993; Salgado et al., 2007). We thus examined the colocalization of $\mathrm{m}^{+}$, with markers for excitatory and inhibitory axon terminals in the cortex (Mrzljak et al., 1993; Salgado et al., 2007). We assessed the optical density and $\mathrm{m}^{+}$ colocalization of excitatory vesicular glutamatergic transporters 1 (VGLUT1) and 2 (VGLUT2), which label axon terminals from putative cortical and subcortical structures, respectively (Fremeau et al., 2004; Hur and Zaborszky, 2005; Hackett et al., 2011; Timbie and Barbas, 2015; Figure 7A). We found a significantly greater density ( $\%$ area) of $\mathrm{VGLUT1}^{+}$terminals in L1 compared to L3 of the LPFC ( $p=0.021$, Two-Way ANOVA area $\times$ layer, Fisher's LSD post hoc; Figure $7 \mathbf{B}$ ), while the density of VGLUT2 ${ }^{+}$terminals was equivalent across layers and areas (Figure 7C). Our data showed that within the supragranular layers, $18-37 \%$ of $\mathrm{VGLUT}^{+}$and VGLUT2 ${ }^{+}$ excitatory terminals were colocalized with $\mathrm{m} 2^{+}$(Figures 7D,E). A significantly greater percent colocalization of VGLUT1 ${ }^{+}$ boutons with $\mathrm{m} 2^{+}$in $\mathrm{L} 2$ compared to L1 was found within ACC (L1 vs. L2: $p=0.012$; Two-Way ANOVA, Fisher LSD post hoc; Figure 7D), while VGLUT2 ${ }^{+}$colocalized with $\mathrm{m}^{+}$ in LPFC L3 was greater compared to L1 (L1 vs. L3 LPFC: $p=0.015$; Figure 7E). Between-area differences were found for the percent of VGLUT2 ${ }^{+}$boutons colocalized with $\mathrm{m}^{+}$. Specifically, VGLUT2 ${ }^{+}$colocalized with $\mathrm{m}^{+}$in LPFC L3 was greater compared to ACC (L3 ACC vs. LPFC: $p=0.017$; Figure 7E).

We next quantified the colocalization of $\mathrm{m} 2$ with vesicular GABA transporter (VGAT), a selectively expressed protein in GABAergic axon terminals (Chaudhry et al., 1998; Figure 7F). Consistent with our previous data (Medalla et al., 2017), we found that ACC had a significantly greater density of $\mathrm{VGAT}^{+}$ puncta compared to LPFC ( $p=0.02$; Figure 7G). Further, within ACC, the density of $\mathrm{VGAT}^{+}$puncta was greater in L1 compared to $\mathrm{L} 2$ and L3 (L1 vs. L2: $p=4.9 \times 10^{-4}$ and L1 vs. L3: $p=3.4 \times 10^{-4}$; Figure 7G). Colocalization analyses of the percent area of total $\mathrm{VGAT}^{+}$colocalized with $\mathrm{m} 2^{+}$in the neuropil revealed no differences between areas and layers, with $\mathrm{m}^{+}$receptor localization on approximately $11 \%$ of inhibitory terminals in the supragranular layers (Figure 7H).

\section{Differential $\mathrm{m2}^{+}$Colocalization With Lamina-Specific $\mathrm{CB}^{+}$and $\mathrm{PV}^{+}$Inhibitory Terminals}

Inhibitory synapses on specific compartments of pyramidal neurons are conferred by neurochemically-distinct interneurons expressing $\mathrm{CB}^{+}$and $\mathrm{PV}^{+}$(DeFelipe, 1997; Kubota et al., 2016). We assessed the proportion of $\mathrm{CB}^{+}$and $\mathrm{PV}^{+} \mathrm{VGAT}^{+}$axon terminals colocalized with $\mathrm{m}^{+}$in $\mathrm{L} 1$ and L3 (Figures 8A-C) using triple EZ-colocalization (Stauffer et al., 2018). Within the supragranular layers, L1 contains mainly distal apical dendrites of pyramidal neurons, while L3, is a more heterogeneous population of dendrites with include proximal dendritic segments and somata (Spruston, 2008). Given that CB interneurons primarily target the distal dendrites (Kawaguchi and Kubota, 1998; DeFelipe et al., 1999) we assessed the percent $\mathrm{VGAT}^{+} \mathrm{CB}^{+}$puncta with $\mathrm{m}^{+}$in $\mathrm{L} 1$ and L3. Given that $\mathrm{PV}$ axons densely target the proximal/perisomatic regions of neurons in L3 and are sparse in L1 (Kawaguchi and Kubota, 1998; Freund and Katona, 2007; Bartos and Elgueta, 2012) we assessed the colocalization of $\mathrm{VGAT}^{+} \mathrm{PV}^{+}$puncta with $\mathrm{m}^{+}$in $\mathrm{L} 3$. The proportion of $\mathrm{CB}^{+}$and $\mathrm{PV}^{+} \mathrm{VGAT}^{+}$ inhibitory terminals expressing $\mathrm{m}^{+}$showed no significant between-area differences (Figure 8C). Within-area, betweensubtype comparisons showed that in L3 of ACC there was a greater percentage of $\mathrm{VGAT}^{+} \mathrm{CB}^{+}$with $\mathrm{m}^{+}$compared to 

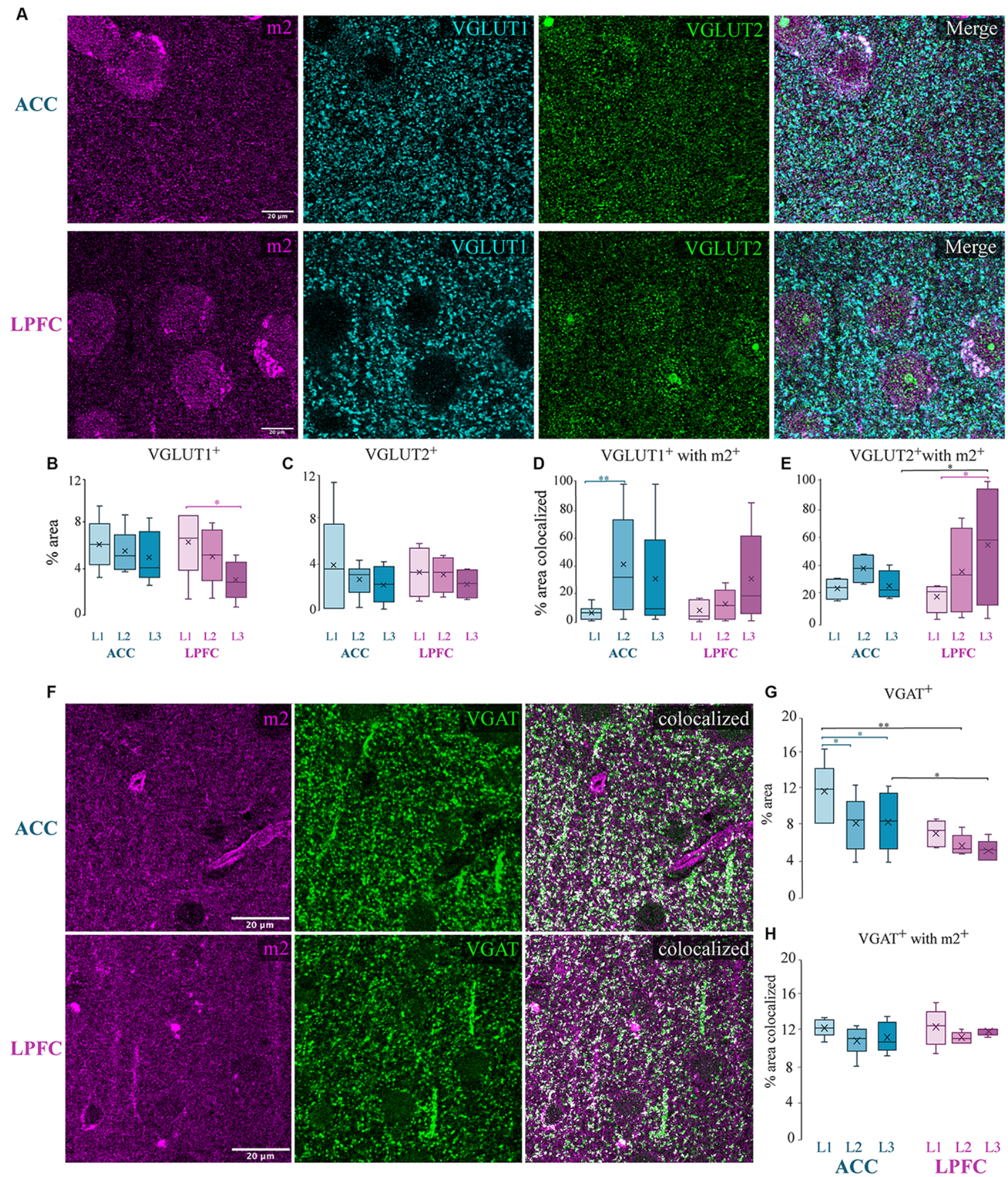

FIGURE 7 | Presynaptic m2 ${ }^{+}$colocalization with excitatory and inhibitory axon terminals. (A) Representative confocal images of m2 ${ }^{+}$(magenta), VGLUT1+ (cyan), and VGLUT2 ${ }^{+}$(green) in the ACC (top) and LPFC (bottom). (B,C) The density (\% area labeled) of VGLUT1+ puncta (B) was significantly greater in L1 of LPFC compared to L3 while VGLUT2 ${ }^{+}$(C) boutons were equivalent across layers and areas. (D,E) Colocalization coefficient (\% area colocalized) of VGLUT1 ${ }^{+}$and VGLUT2 ${ }^{+}$with $\mathrm{m}^{+}$. (D) In ACC, a significantly greater percent of VGLUT1+ boutons expressing m2 ${ }^{+}$was found in L2 compared to L1. (E) In LPFC, a significantly greater percent of VGLUT2 ${ }^{+}$boutons expressing $\mathrm{m}^{+}{ }^{+}$was found in L3 compared to L1. (F) Representative confocal images of m2 ${ }^{+}$(magenta) and VGAT ${ }^{+}$(green), and colocalized particles in white. Scale bar $20 \mu \mathrm{m}$. (G) \% area label showing that the laminar density of VGAT ${ }^{+}$was significantly greater within the ACC. (H) Colocalization coefficient showing $\%$ area of VGAT ${ }^{+}$colocalized with $\mathrm{m}^{+}$: approximately $11 \%$ of inhibitory terminals were colocalized with m2 $2^{+}$in both the $\mathrm{ACC}$ and LPFC. ${ }^{*} p \leq 0.05,{ }^{* *} p \leq 0.01$. 


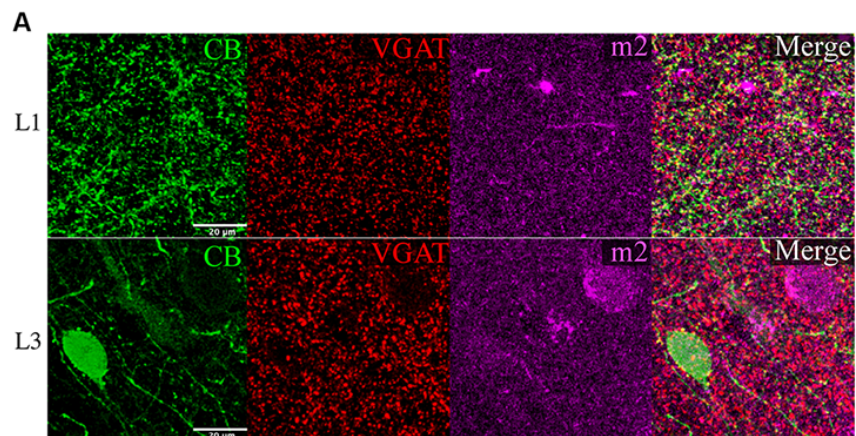

\section{C $\quad \mathrm{ACC} \quad \mathrm{LPFC}$}

B
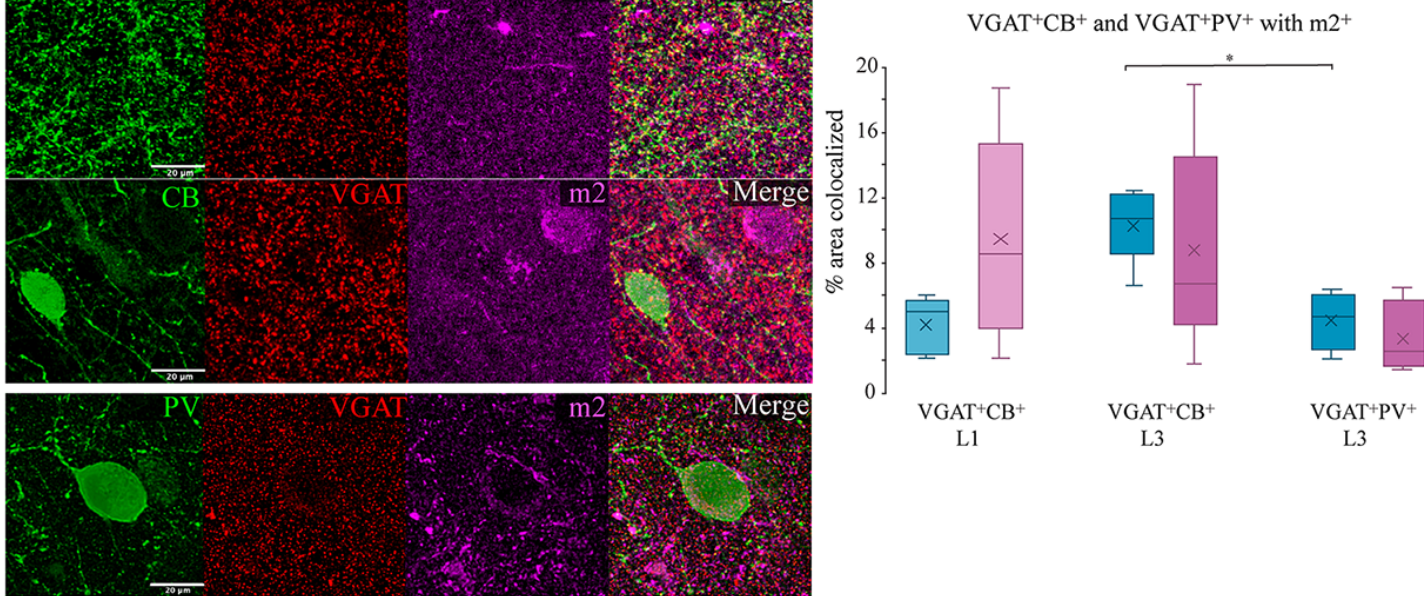

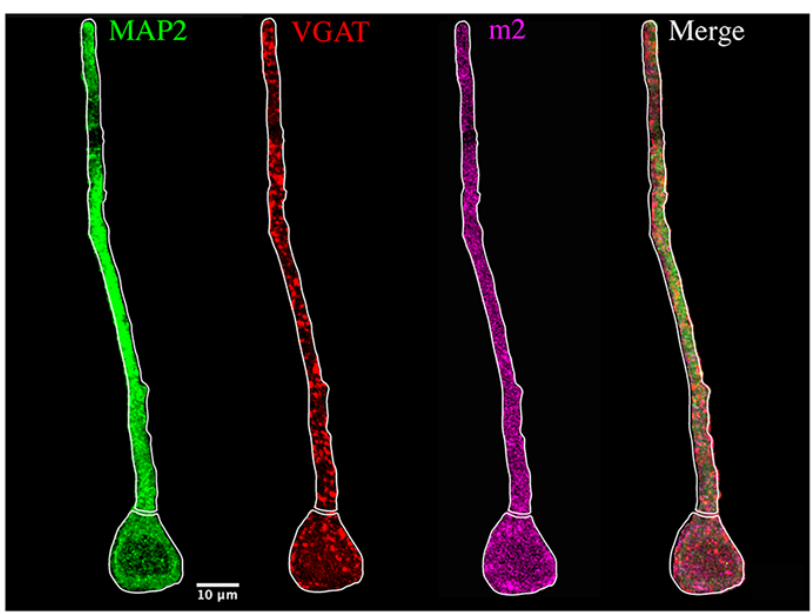

G

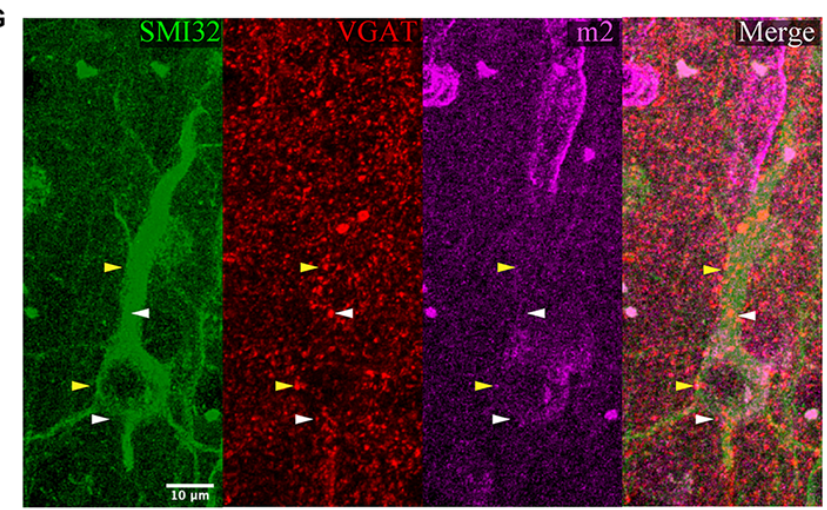

E
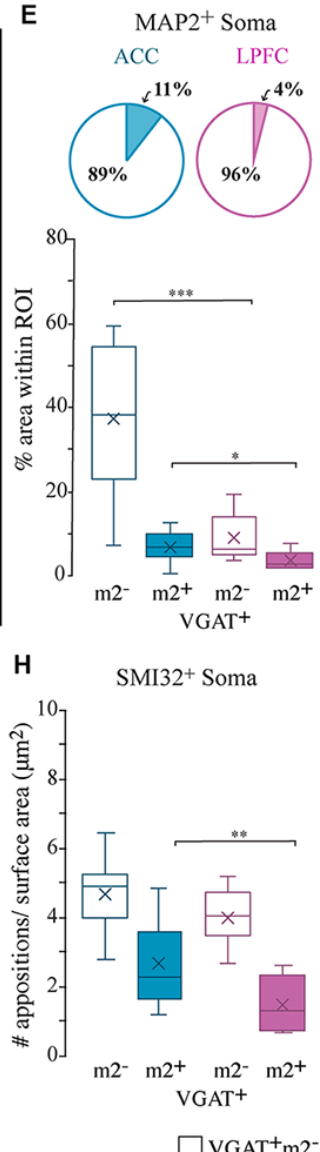

SMI $32+$ Soma
$F$
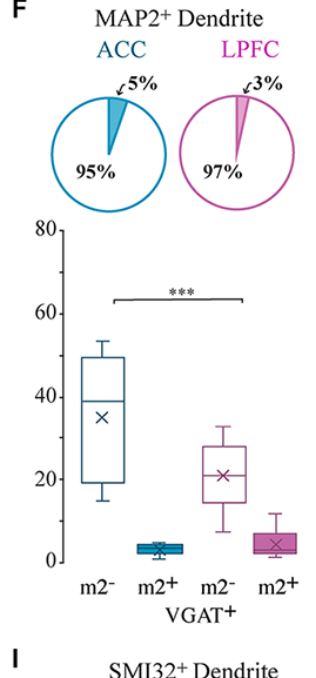

FIGURE 8 | Co-localization of $\mathrm{m}^{+}$with neurochemically distinct and compartment-specific inhibitory axon terminals. (A,B) Representative confocal images of $\mathrm{VGAT}^{+}$(red), m2 ${ }^{+}$(magenta) terminals with terminals from either (A) CB (green) in L1 (top) or L3 (bottom) or (B) PV (green) in L3. (C) Box and whisker plots of \% area of $\mathrm{m} 2$ colocalization with VGAT ${ }^{+} / \mathrm{CB}^{+}$in $\mathrm{L} 1$ (light hue) and $\mathrm{L} 3$ (dark hue) and with VGAT ${ }^{+} / \mathrm{PV}^{+} \mathrm{L} 3$ (dark hue). Within the ACC, L3 had significantly greater colocalization of $\mathrm{CB}^{+} \mathrm{VGAT}{ }^{+}$terminals with $\mathrm{m}^{+}$than $\mathrm{PV}^{+} \mathrm{VGAT}{ }^{+}$with $\mathrm{m}^{+}$. (D-F) VGAT + /m2 + terminals apposed (putative synapses) to specific somatodendritic

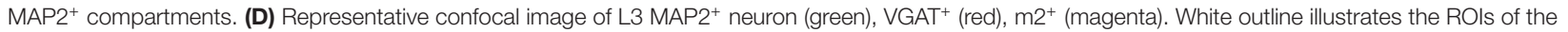
proximal apical dendrite and the soma. Scale bar $10 \mu \mathrm{m}$. (E,F) The relative proportion (top) and density (bottom) of colocalized VGAT ${ }^{+} 2^{-}$and VGAT ${ }^{+} 2^{+}$ appositions on the (E) soma and (F) proximal apical dendrite of MAP2 ${ }^{+}$neurons in the ACC ( $n=10$ cells) and LPFC ( $n=10$ cells). (G) Representative confocal image of L3 SMI-32+ neuron (green), VGAT ${ }^{+}$(red), m2 ${ }^{+}$(magenta) showing proximal dendritic and somatic VGAT ${ }^{+}$appositions. White arrows denote examples of VGAT ${ }^{+}$ only appositions and yellow arrows denote VGAT ${ }^{+} 2^{+}$apposition. Scale bar $20 \mu \mathrm{m}$. (H,I) The density of VGAT ${ }^{+} \mathrm{m}^{+}$appositions (putative synapses) per cell was significantly greater in the $\mathbf{( H )}$ somatic (appositions $/ \mu \mathrm{m}^{2}$ ) but not in the $\mathbf{( I )}$ dendritic (appositions/ $\mu \mathrm{m}$ ) compartments of neurons in the ACC compared to the LPFC. ${ }^{*} p \leq 0.05,{ }^{* *} p \leq 0.01,{ }^{* * *} p \leq 0.001$. 
VGAT $^{+} \mathrm{PV}^{+}$with $2^{+}(p=0.043$, Two-Way ANOVA, Fisher's LSD post hoc; Figure 8C).

\section{Colocalization of $\mathrm{m}^{+}$With GABAergic Terminals Onto Pyramidal Neuron Subcellular Compartments}

We quantified the density of VGAT ${ }^{+} \mathrm{m}^{-}$and $\mathrm{VGAT}^{+} \mathrm{m}^{+}$ appositions on proximal apical dendritic or somatic ROI compartments of individual L3 MAP2 ${ }^{+}$(Figure 8D) and SMI$32^{+}$pyramidal neurons (Figure 8G) in the ACC $\left(n=10 \mathrm{MAP}^{+}\right.$ cells, $n=10 \mathrm{SMI}-32^{+}$, from five cases) and LPFC ( $n=10 \mathrm{MAP}^{+}$ cells, $n=10 \mathrm{SMI}-32^{+}$cells, from five cases). Compared to LPFC, we found that ACC L3 $\mathrm{MAP}^{+}$neurons had a significantly higher density of $\mathrm{VGAT}^{+} \mathrm{m} 2^{-}$puncta on the soma and apical dendrite (ACC vs. LPFC: soma: $p=8.60 \times 10^{-6}$, apical dendrite: $p=8.60 \times 10^{-6}$, One-Way ANOVA; Figures 8E,F). However, for $\mathrm{VGAT}^{+} \mathrm{m}^{+}$appositions, the two areas were equivalent with regards to appositions on proximal apical dendrites (Figure 8F), but differed with regards to appositions on the soma. The ACC had a higher density (\% area) of double-labeled $\mathrm{VGAT}^{+} \mathrm{m}^{+}$ puncta as apposed to the somatic compartment (ACC vs. LPFC soma $p=0.03$; Figure 8E). The population of $\mathrm{VGAT}^{+} \mathrm{m}^{+}$in the somatic compartment represents $\sim 11 \%$ of the total $\mathrm{VGAT}^{+}$ appositions in ACC neurons, which is significantly greater than LPFC neurons, with only $\sim 4 \%$ of the total $\mathrm{VGAT}^{+}$appositions co-expressing $\mathrm{m}^{+}$(Figure $\mathbf{8 E}$ ).

Consistent with patterns seen with $\mathrm{MAP}^{+}$pyramidal neurons, the subpopulation of L3 SMI- $32^{+}$pyramidal neurons had greater densities of $\mathrm{VGAT}^{+} \mathrm{m}^{-}$appositions on proximal apical dendrites (ACC vs. LPFC: $p=9.82 \times 10^{-3}$; Figure 8I) and $\mathrm{VGAT}^{+} \mathrm{m} 2^{+}$perisomatic appositions in ACC compared to LPFC (ACC vs. LPFC soma: $p=0.01$; Figure $8 \mathbf{H}$ ). In summary, these data show that $\mathrm{m}^{-}$proximal dendrite/perisomatic inhibitory inputs and the subset of $\mathrm{m}^{+}$perisomatic inhibitory inputs are greater in ACC than LPFC.

\section{$\mathrm{m2}^{+}$Localization on Inhibitory VGAT ${ }^{+}$Axon Cartridges}

Axo-axonal GABAergic inputs to the axon initial segment confer a functionally powerful mode of inhibition (Somogyi, 1977; DeFelipe et al., 1989; Inan et al., 2013). These specialized inhibitory synapses can be identified by the presence of $\mathrm{VGAT}^{+}$ axon "cartridges"-puncta arranged in rows perpendicular to the pial surface (Somogyi, 1977) that are about $26-46 \mu \mathrm{m}$ in length (Figure 9A). We found that the mean length of $\mathrm{VGAT}^{+}$ cartridges was significantly longer in the ACC $(n=200$ cartridges from 5 cases) compared to the LPFC $(n=300$ cartridges from 6 cases; $p=7.6 \times 10^{-5}$, One-Way ANOVA; Figure 9B). However, there was no between-area difference in the density of $\mathrm{VGAT}^{+}$cartridges in the neuropil quantified using stereological counting procedures (Figure 9C).

Using stereological counting procedures, we quantified and classified L3 VGAT ${ }^{+}$cartridges depending on their strength of expression of $\mathrm{m}^{+}$as follows: strongly labeled $\mathrm{m} 2^{++}(>50 \%$ of $\mathrm{VGAT}^{+}$cartridge area labeled was colocalized with $\mathrm{m} 2$ ); lightlylabeled $\mathrm{m}^{+}$( $\leq 50 \%$ ); or $\mathrm{m}^{-} / \mathrm{VGAT}^{+}$only (Figure 9D). Among the total number of $\mathrm{VGAT}^{+}$cartridges in the ACC, the majority were $\mathrm{m}^{++}(53 \%)$ or $\mathrm{m} 2^{+}$cartridges $(40 \%)$ and the minority did not express $\mathrm{m}^{-}\left(\mathrm{VGAT}^{+}\right.$only, $7 \%$; $p=4.7 \times 10^{-8}$, Chi-Square, and Bonferroni post hoc, Figure 9F). This was in marked contrast to the LPFC where the majority of $\mathrm{VGAT}^{+}$cartridges were either lightly-labeled with $\mathrm{m}^{+}(56 \%)$ or did not express $\mathrm{m}^{-}{ }^{-}$VGAT $^{+}$ only, $\sim 36 \%$ ), and the $\mathrm{m}^{++}$cartridges represented the minority $\left(8 \% ; p=2.7 \times 10^{-8}\right)$. Between-area comparisons revealed that the ACC had a significantly greater density $\left(p=4.8 \times 10^{-3}\right.$, One-Way ANOVA $)$ and proportion $\left(p=2.10 \times 10^{-12}\right.$, Fisher Exact Test) of $\mathrm{m}^{++}$cartridges compared to LPFC, while the LPFC had greater density $\left(p=4.27 \times 10^{-4}\right.$, One-Way ANOVA $)$ and proportion $\left(p=6.50 \times 10^{-7}\right.$, Fisher Exact Test) of $\mathrm{m}^{-} / \mathrm{VGAT}^{+}$only cartridges (Figures 9E,F). We assessed whether the $\mathrm{VGAT}^{+}$cartridges classified as lightly $\mathrm{m}^{+}$ labeled vs. strongly $\mathrm{m}^{++}$labeled in the two areas differed in their densities of individual $\mathrm{VGAT}^{+} \mathrm{m}^{-}$and $\mathrm{VGAT}^{+} \mathrm{m}^{+}$ boutons per cartridge. $\mathrm{VGAT}^{+} \mathrm{m} 2^{-}$and $\mathrm{VGAT}^{+} \mathrm{m}^{+}$boutons were distributed randomly along the length of each cartridge. Within both areas, cartridges classified as strongly expressing $\mathrm{m}^{++}$had a significantly greater proportion (data not shown; ACC: $p=2.23 \times 10^{-8}$; LPFC: $p=8.23 \times 10^{-10}$ ) and density of $\mathrm{VGAT}^{+} \mathrm{m}^{+}$labelled boutons compared to the lightly labelled $\mathrm{m}^{+}$cartridge type (ACC: $p=8.21 \times 10^{-9}$; LPFC: $p=3.26 \times 10^{-5}$, Two-Way ANOVA, Fisher LSD post hoc; Figure 9G). About $\sim 52-59 \%$ of $\mathrm{VGAT}^{+}$boutons in each $\mathrm{m}^{++}$cartridge, but only $\sim 33-37 \%$ in each $\mathrm{m}^{+}$cartridge, expressed $\mathrm{m} 2$. Significant between-area differences were found only for $\mathrm{m}^{++}$cartridges, with the density of $\mathrm{VGAT}^{+} \mathrm{m} 2^{+}$labelled boutons greater in ACC than in LPFC $\mathrm{m}^{++}$cartridges (Twoway ANOVA, "area" $\mathrm{x}$ "cartridge type" interaction, $p=0.03$; $\mathrm{m}^{++}$cartridges in ACC vs. LPFC $p=0.0006$, Fisher LSD post hoc; Figure 9G). Overall, these data show that the densities of L3 $\mathrm{VGAT}^{+}$cartridges strongly expressing $\mathrm{m}^{++}$receptors in the neuropil and of $\mathrm{VGAT}^{+} \mathrm{m}^{+}$labeled boutons within these cartridges were greater in ACC than in the LPFC.

\section{DISCUSSION}

Two functionally-distinct prefrontal regions involved in executive control, the LPFC and the ACC (Rushworth et al., 2011), differ in their structural relationship with the cholinergic modulatory system (Mesulam et al., 1992; Ghashghaei and Barbas, 2001). Figure 10 summarizes the normalized density of excitatory and inhibitory neuron types expressing mAChRs (Figure 10A) and the subcellular distribution of $\mathrm{m} 1$ and $\mathrm{m} 2$ receptors on a $\mathrm{L} 3$ pyramidal neuron and on the distinct inhibitory neuron subtypes with specific somatodendritic and axonal targets (Figure 10B) in these two prefrontal areas.

\section{Regional Differences in the Expression of mAChR on Subpopulations of Pyramidal Neurons}

Our data revealed regional and laminar differences in the densities of excitatory subpopulations expressing $\mathrm{m}^{+}$or $\mathrm{m}^{+}$. Consistent with previous studies, we found that $\mathrm{MAP}^{+}$ pyramidal neurons, and the subset labeled by SMI- $32^{+}$, were 


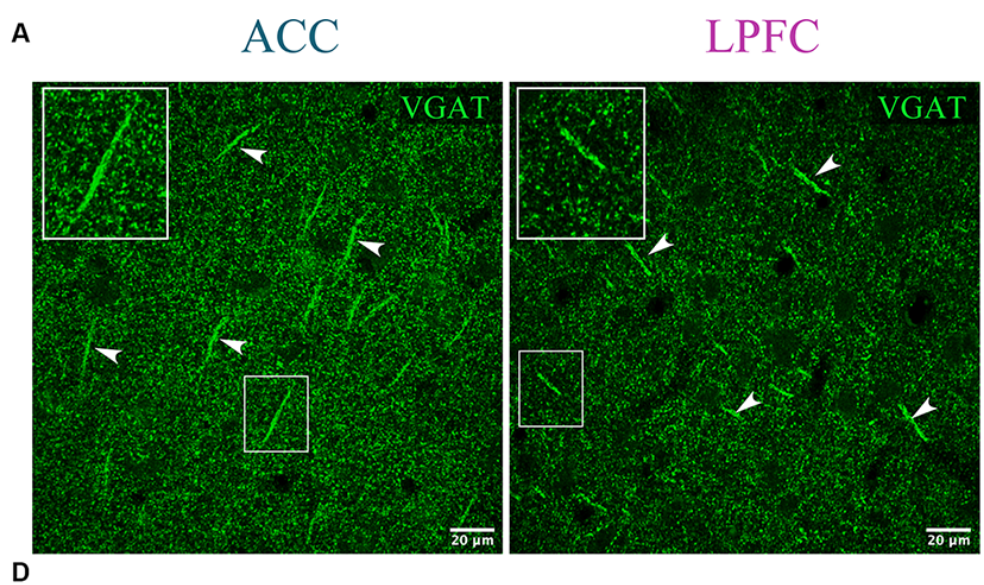

B $\mathrm{VGAT}^{+}$

Cartridge Length

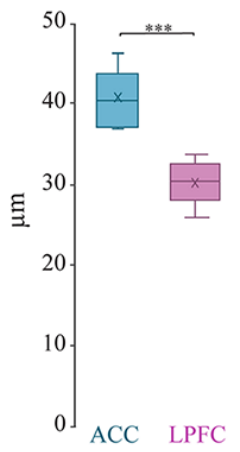

VGAT $^{+}$

Cartridge Density

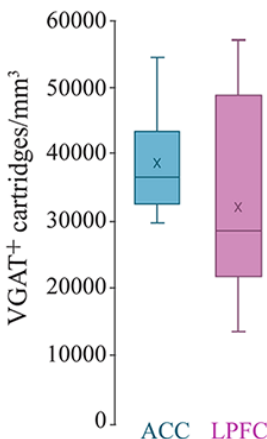

D
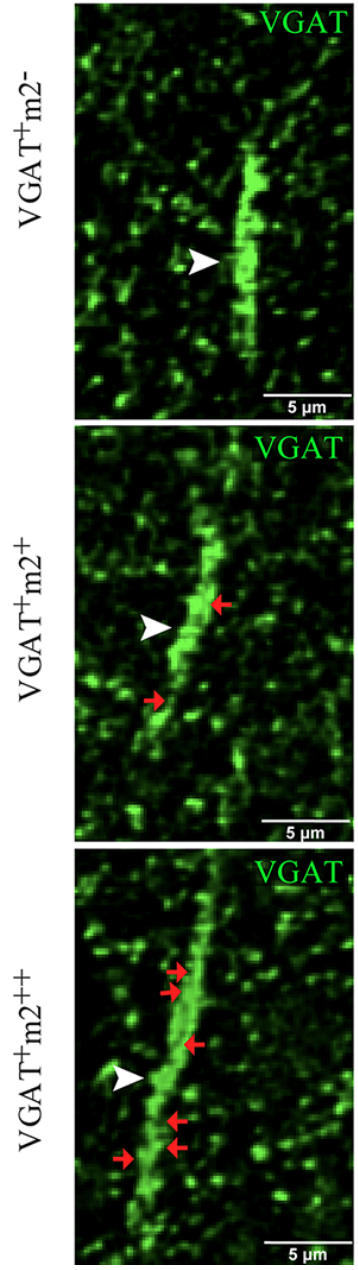
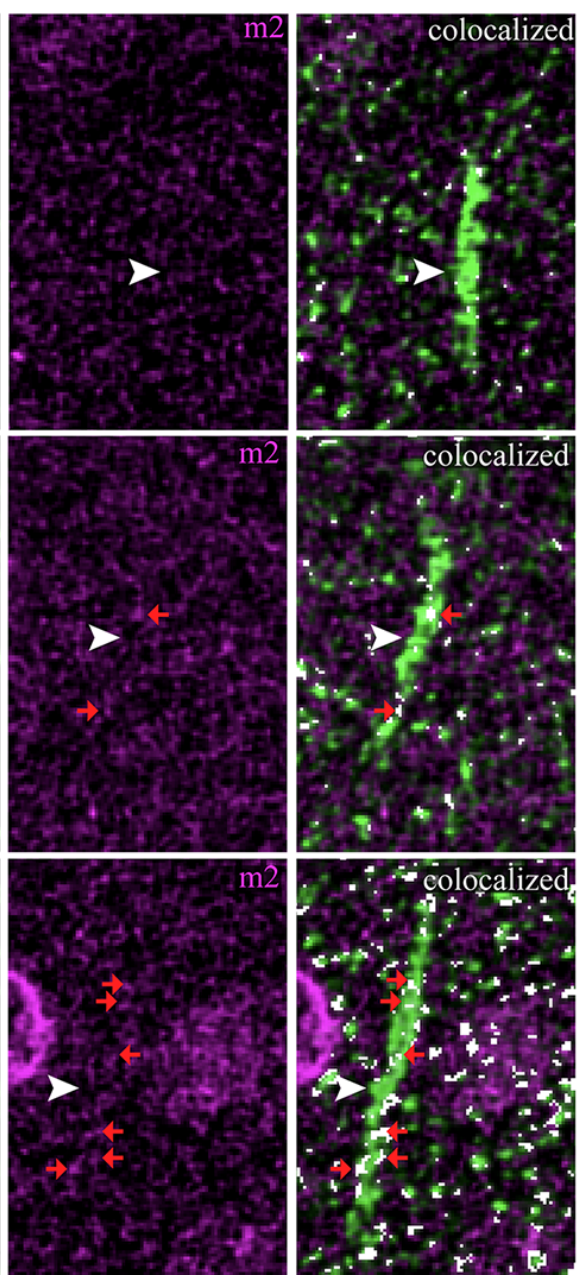

E Density of $\mathrm{m} 2$ expressing $\mathrm{VGAT}^{+}$cartridges

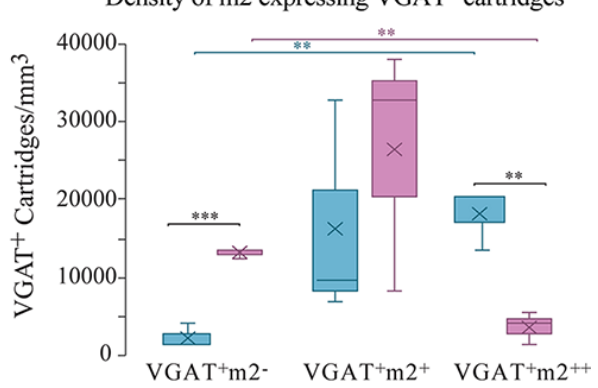

F

Distribution of $\mathrm{VGAT}^{+}$cartridge types

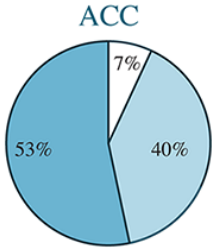

LPFC

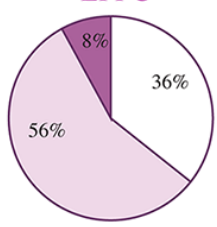

$\square \mathrm{VGAT}^{+} \mathrm{m}^{-} \quad \square \mathrm{VGAT}^{+} \mathrm{m}^{+}$

$\square \mathrm{VGAT}^{+} \mathrm{m} 2^{++}$

G

Density of $\mathrm{m} 2^{-}$and $\mathrm{m} 2^{+}$boutons/cartridge

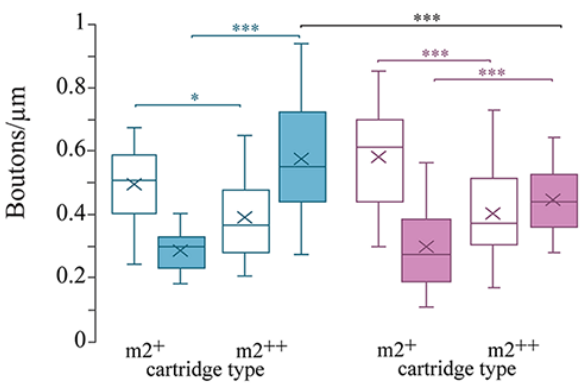

$\mathrm{ACC}$

LPFC

$\square \mathrm{VGAT}^{+}{ }^{\mathrm{m} 2} 2^{-}$bouton $\quad \square \mathrm{VGAT}^{+} \mathrm{m}^{+}$bouton

FIGURE 9 | Differential $\mathrm{m}^{+}$expression of VGAT ${ }^{+}$cartridges in the ACC and LPFC. (A) Representative confocal image of distinct VGAT ${ }^{+}$cartridges (arrow) in ACC (left) and LPFC (right). Boxed insets are shown in higher magnification (in the upper left corner of each image) to highlight the difference in length of VGAT ${ }^{+}$cartridges between the two areas. (B) The ACC revealed a significantly greater cartridge length compared to the LPFC. (C) The density of VGAT ${ }^{+}$cartridges (number per mm ${ }^{3}$ ) was equivalent between the two areas. (D) Representative image of either VGAT ${ }^{+}$only (top), VGAT ${ }^{+}$with lightly-labeled $\mathrm{m} 2^{+}$(middle) or with strongly-labeled $\mathrm{m} 2^{++}$ (bottom), the white arrows show the VGAT ${ }^{+}$cartridges, and examples of $\mathrm{VGAT}^{+} \mathrm{m} 2^{+}$boutons along each cartridge are indicated by red arrows. Note that $\mathrm{m} 2^{+}$and $\mathrm{m}^{++}$cartridges are made up of rows of both VGAT ${ }^{+} 2^{-}$and VGAT ${ }^{+} 2^{+}$boutons distributed along the length of each cartridge. Scale bar $5 \mu \mathrm{m}$. (E) The density of $\mathrm{VGAT}^{+}$only cartridges was greater in the LPFC, while the ACC had greater density of $\mathrm{m} 2^{++}$VGAT cartridges. (F) The relative proportion of VGAT ${ }^{+}$only cartridges (white), lightly-labeled $\mathrm{m}^{+}$(light colored) or strongly-labeled $\mathrm{m}^{++}$(dark colored) VGAT+ cartridges in ACC (left) and LPFC (right). * $p \leq 0.05$. (G) The density of individual VGAT ${ }^{+} \mathrm{m} 2^{-}$(unfilled bars) and VGAT ${ }^{+} 2^{+}$(filled bars) boutons along the length of distinct VGAT ${ }^{+}$cartridge types classified as either lightly-labeled $\mathrm{m}^{+}{ }^{+}$or strongly-labeled $2^{++}$in ACC and LPFC. ${ }^{*} p \leq 0.05,{ }^{* *} p \leq 0.01,{ }^{* * *} p \leq 0.001$ 
A

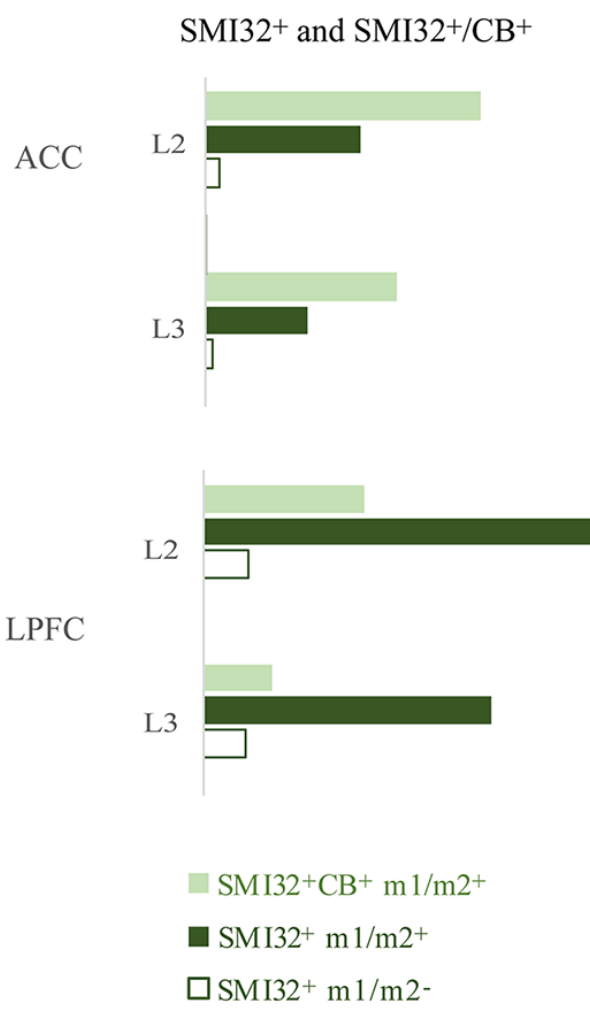

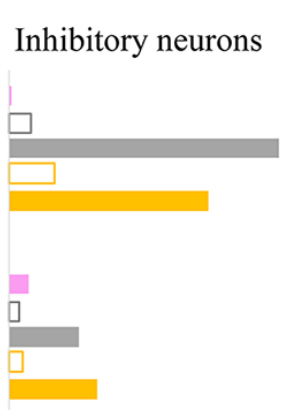

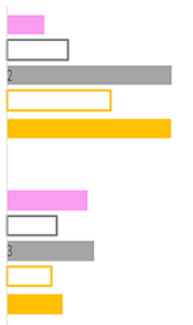

$\mathrm{PV}^{+} \mathrm{m}^{+}$

- $\mathrm{CR}^{+} \mathrm{m}^{2+}$

$\mathrm{CR}^{+} \mathrm{m} 2-$

$\square \mathrm{CB}^{+} \mathrm{m}_{2}{ }^{+} \square \mathrm{CB}^{+} \mathrm{m} 2-$
B

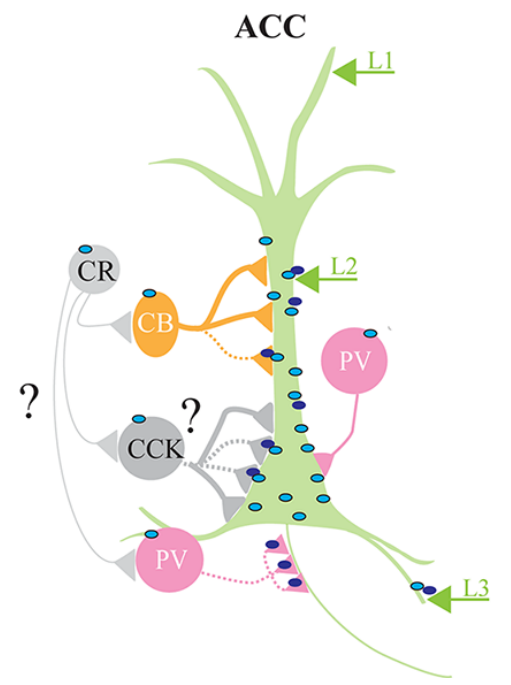

LPFC

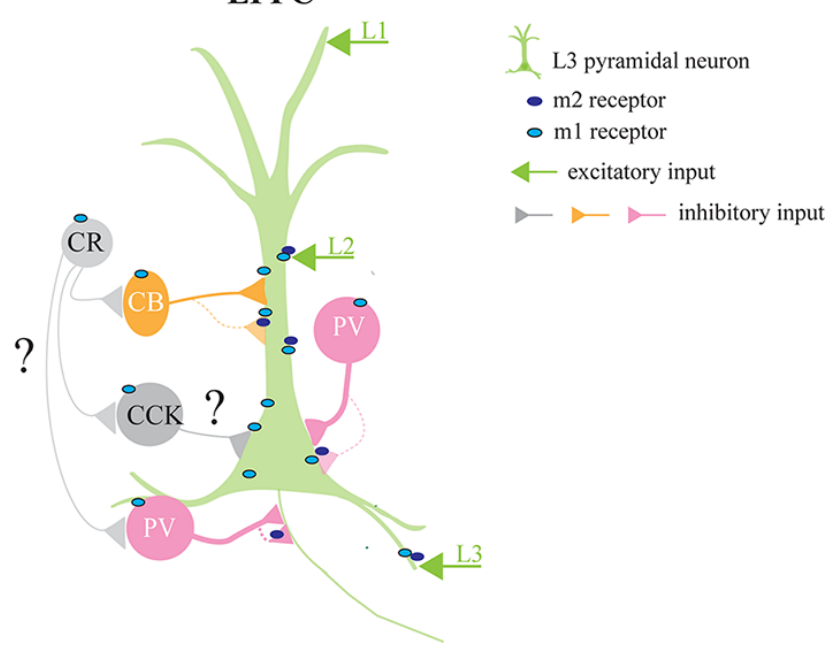

FIGURE 10 | Summary of ACC and LPFC micro-circuitry influenced by muscarinic receptors. (A) Normalized densities of differentially distributed excitatory and inhibitory neuronal populations expressing mAChRs in ACC and LPFC. LPFC had a greater density of $\mathrm{m} 1^{+} / \mathrm{m}^{+} \mathrm{SMI}-32^{+}$while ACC had a greater density of $\mathrm{m} 1^{+} / \mathrm{m}^{+} \mathrm{SMl}-32^{+} \mathrm{CB}^{+}$pyramidal neurons. The two areas differed with regards to $\mathrm{m}^{+}$inhibitory neurons, with inhibitory neurons in the ACC having a greater extent of $\mathrm{m}^{+}$expression than in the LPFC. (B) Micro-circuit schematic based on the main findings of the subcellular distribution of postsynaptic $\mathrm{m} 1^{+}$on $\mathrm{MAP2} 2^{+}$dendrites and $\mathrm{m}^{+}$inhibitory terminals on specific somatodendritic and axonal compartments. The number of connections and line thickness represents the relative strength of connection, while the dotted line indicates $\mathrm{m} 2$ mediated pre-synaptic suppression. Compared to LPFC, L3 ACC pyramidal neurons had a greater density of m1+ on the dendritic and somatic compartments. The dendrites of these ACC pyramidal neurons had a greater density of total VGAT ${ }^{+}$, including $\mathrm{m}^{+} \mathrm{VGAT}{ }^{+}$, inhibitory inputs likely from $\mathrm{CB}^{+}$(yellow) neurons. The LPFC pyramidal neurons received a lower density of perisomatic input, mostly belonging to $\mathrm{PV}^{+}$interneurons (Medalla et al., 2017), and only a small subset expressed $m 2^{+}$(pink). In contrast, the ACC had a greater density of VGAT ${ }^{+} m 2^{+}$and VGAT ${ }^{+} m 2^{-}$inhibitory inputs, presumably from non-PV basket cells (great) with a subset likely from CCK ${ }^{+}$interneurons (Medalla et al., 2017). Note that the m2 localization on CR and CCK terminations (grey) remains unknown in the present study. Finally, compared to LPFC, the ACC had a greater density of axonal targeting VGAT ${ }^{+} \mathrm{m}^{+}$cartridges, presumably from $\mathrm{PV}^{+}$ chandelier cells. 
denser in LPFC than ACC (Barbas et al., 2018). However, a novel finding showed a greater density of the subset of SMI$32^{+}$pyramidal neurons co-expressing calcium-binding protein $\mathrm{CB}^{+}$in the ACC L3, compared to the LPFC (Figure 10). While $\mathrm{CB}$ has been used to mark inhibitory neurons in the primate cortex (DeFelipe, 1997), previous work has identified a small subset of lightly-expressing $\mathrm{CB}^{+}$pyramidal neurons (Hof and Nimchinsky, 1992; DeFelipe, 1997; Kondo et al., 1999; Dombrowski et al., 2001), particularly within the paralimbic cortices and the hippocampus (Seress et al., 1991; Wang et al., 2021). The enrichment of $\mathrm{CB}^{+}$in $\mathrm{CA} 1$ pyramidal neurons is interesting in light of the robust degrees of calcium-dependent dendritic and synaptic plasticity in these cells (Molinari et al., 1996; Westerink et al., 2012), and the role of $\mathrm{CB}^{+}$expressing neurons in memory formation (Dumas et al., 2004; Li et al., 2017). Pyramidal neurons expressing SMI- $32^{+}$have been identified as a selectively vulnerable population in Alzheimer's disease and other neurodegenerative diseases (Morrison and Hof, 2002; Bussiere et al., 2003). Therefore, our finding of $\mathrm{m}^{+}$ and $\mathrm{m}^{+}$expressing SMI- $32^{+} \mathrm{CB}^{+}$pyramidal neurons within the ACC warrants further investigation to understand the role of cholinergic modulation in memory and plasticity, and its implications on developing therapies for neurodegenerative and neuropsychiatric diseases (Levey, 1996; Moran et al., 2019; Foster et al., 2021).

\section{Denser $\mathrm{m} 1$ Expression in MAP2 Dendrites and Somata of ACC Pyramidal Neurons}

In the $\mathrm{L} 1$ neuropil, we found a greater expression of $\mathrm{ml}^{+}$in LPFC compared to ACC. However, in L1-L2 of LPFC, only $\sim 18-21 \%$ of $\mathrm{m}^{+}$were expressed on $\mathrm{MAP}^{+}$dendrites, which is lower than in ACC, where $\sim 29-37 \%$ of $\mathrm{m}^{+}$were expressed on $\mathrm{MAP}^{+}$dendrites. This suggests that the net functional effect of $\mathrm{m}^{+}$activation on L1-L2 MAP2 ${ }^{+}$dendrites, which are predominantly distal apical dendrites (Peters and Sethares, 1991), is greater in ACC than LPFC. Indeed, although a higher number of $\mathrm{MAP}^{+} \mathrm{m}^{+}$neurons was found in LPFC, the density of $\mathrm{ml}^{+}$ within somatic and proximal apical dendritic compartments of individual $\mathrm{MAP}^{+} \mathrm{L}^{+}$pyramidal neurons was greater in ACC than LPFC (Figure 10). The greater density of dendritic $\mathrm{ml}^{+}$ expression in ACC pyramidal neurons is interesting in light of the role that muscarinic receptors play in modulating spiketiming-dependent dendritic plasticity (Yamasaki et al., 2010) and long-term potentiation (LTP; Markram and Segal, 1990; Marino et al., 1998; Dennis et al., 2016). The differential distribution of $\mathrm{ml}^{+}$receptors across laminar cell types and compartments in ACC and LPFC suggest distinct cholinergic modulation of specific circuits (Coppola et al., 2016; Disney and Higley, 2020). The greater expression of $\mathrm{m}^{+}$in LPFC L1, compared to ACC, is likely due to non-MAP2 cells and compartments (Caceres et al., 1984; Peters and Sethares, 1991), such as axons, glial cells (Dombrowski et al., 2001), or weakly-stained interneuron dendrites (Gabbott, 2016; Schuman et al., 2019) enriched in this layer. L1 receives cortico-cortical "feedback" inputs and diffuse thalamic inputs that are thought to be important for shaping task-relevant signals (Roland, 2002; Jones, 2009). Our data suggest that these $\mathrm{L} 1$ inputs targeting $\mathrm{MAP}^{+}$dendrites in
ACC and non-MAP2 ${ }^{+}$cellular compartments in LPFC are more modulated by $\mathrm{m}^{+} \mathrm{mAChR}$ activation. Future studies are needed to assess the subcellular localization of $\mathrm{m} 1$ on these non-MAP2 cells and their relationship with extrinsic inputs in the upper layers.

\section{Presynaptic m2 Receptors Are Selectively Localized on Excitatory Axon Terminals in ACC and LPFC}

Electron microscopic work in rhesus monkeys showed that presynaptic $\mathrm{m} 2^{+}$receptors were predominantly localized to glutamatergic boutons forming synapses on dendritic spines (Mrzljak et al., 1993). We observed that $\mathrm{m}^{+}$receptors largely colocalized with presynaptic excitatory $\mathrm{VGLUT1}^{+}$and VGLUT2 $^{+}$axon terminals, suggesting a capacity for cholinergic suppression of cortico-cortical and cortico-subcortical excitatory transmission in both ACC and LPFC (Mrzljak et al., 1998; Hasselmo and Sarter, 2011; Medalla and Barbas, 2012). However, in the $\mathrm{ACC}, \mathrm{m} 2^{+}$receptors were predominantly expressed on $\mathrm{VGLUT1}^{+}$than on $\mathrm{VGLUT2}^{+}$terminals indicating greater modulation of cortico-cortical axon terminals, consistent with previous findings in the PFC (Medalla and Barbas, 2012), as well as in the visual cortex (Disney et al., 2006). Interestingly, $\mathrm{VGLUT}^{+} \mathrm{m}^{+}$boutons were denser in $\mathrm{L} 2 / \mathrm{L} 3$ compared to $\mathrm{L} 1$ in $\mathrm{ACC}$, while $\mathrm{VGLUT}^{+} \mathrm{m} 2^{+}$boutons were denser in L2/L3 compared to L1 in LPFC. These data suggest laminar and pathway-specificity of $\mathrm{m}^{+}$modulation of inputs within each area (Medalla and Barbas, 2012), with L2/3 cortico-cortical inputs in ACC but L2/3 cortico-subcortical inputs in LPFC may be suppressed by ACh to a greater extent compared to L1 inputs. In studies of rodent piriform cortex (Hasselmo and Bower, 1992) and monkey visual cortices (Disney et al., 2006; Disney and Aoki, 2008), ACh is thought to selectively suppress intrinsic cortico-cortical recurrent excitatory connections, but enhance extrinsic "bottom-up" inputs (i.e., thalamic input) for signal selection. However, our current data suggest that the relative degree of ACh suppression of distinct "bottom-up" vs. "topdown" pathways is region-specific. Indeed, in the primate visual system, the degree of ACh "top down" attentional modulation differs across areas, which is more robust in primary visual cortex (V1) and LPFC frontal eye fields (FEF), compared to the visual middle temporal area (MT; Herrero et al., 2008, 2017; Thiele et al., 2012; Veith et al., 2021). Further, previous anatomical work in monkey LPFC (Medalla and Barbas, 2012) showed differences in presynaptic $\mathrm{m} 2$ expression on distinct "top-down" prefrontal pathways, with $\mathrm{m}^{+}$ACC to LPFC inputs more predominant than $\mathrm{m}^{+}$LPFC to LPFC recurrent connections. The VGLUT2 ${ }^{+}$ axon terminals in LPFC L2/3 examined here include the subset of thalamic "bottom-up" inputs from the higher-order mediodorsal and motor ventral anterior nuclei (Zikopoulos and Barbas, 2007), while VGLUT1 ${ }^{+}$terminals in ACC L2/3 include the subset of dense limbic "top-down" cortico-cortical input from entorhinal and orbitofrontal cortex (Timbie and Barbas, 2014; Calderazzo et al., 2021). Our data suggest preferential m2-mediated ACh suppression of these specific pathways. Future studies incorporating functional, anatomical tract-tracing, and 
computational work are needed to examine and confirm these layer- and pathway-specific patterns of cholinergic presynaptic modulation mediated by $\mathrm{m} 2$, and by other muscarinic and nicotinic receptor subtypes.

\section{Differential Expression of $\mathrm{m} 2$ Receptors in Neurochemically Distinct Inhibitory Neurons}

The diverse distributions of $\mathrm{m}^{+}$and $\mathrm{m} 2^{+}$expressing inhibitory interneuron subtypes targeting distinct pyramidal neuronal compartments can differentially influence the activity in ACC and LPFC (DeFelipe, 1997; Kubota et al., 2016). While we found that almost all (92-100\%) interneuron subtypes examined expressed $\mathrm{m}^{+}$in both prefrontal areas, laminar and regional density differences were found. $\mathrm{PV}^{+} \mathrm{ml}^{+}$neurons were densest in LPFC L3, while $\mathrm{CB}^{+} \mathrm{ml}^{+}$and $\mathrm{CR}^{+} \mathrm{ml}^{+}$neurons were densest in ACC L2. The proportion of $\mathrm{m}^{+}$expressing neurons in each inhibitory neuron subtype differed between areas, with ACC exhibiting a higher proportion of $\mathrm{PV}^{+} \mathrm{m} 2^{+}, \mathrm{CB}^{+} \mathrm{m} 2^{+}$, and $\mathrm{CR}^{+} \mathrm{m} 2^{+}$in L2 and L3 compared to LPFC. Our results suggest that while all interneurons are capable of being activated by $\mathrm{m} 1$ muscarinic receptors, the ability for $\mathrm{m} 2$ mediated muscarinic suppression differs depending on subtype, region and layer (Figure 10).

\section{Regional Differences in m2 Presynaptic Localization on Inhibitory Inputs Targeting Distinct Subcellular Postsynaptic Compartments}

Consistent with the findings on the proportion of $\mathrm{m} 2$ expressing inhibitory neurons, direct examination of inhibitory terminals targeting distinct pyramidal neuron compartments revealed greater densities of $\mathrm{m}^{+}$inhibitory terminals in the ACC compared to the LPFC. These data collectively suggest that $\mathrm{m} 2^{+}$mediated muscarinic suppression of inhibitory neuron neurotransmitter release is likely to be greater in ACC than in LPFC.

Our findings show that the densities of somatic VGAT ${ }^{+} \mathrm{m}^{+}$ inhibitory inputs on $\mathrm{L} 3 \mathrm{MAP}^{+}$and SMI- $32^{+}$pyramidal neurons were greater in ACC than LPFC. We previously found that in LPFC, the majority of perisomatic inhibition is mediated by $\mathrm{PV}^{+}$ interneurons, but in ACC, perisomatic inputs from non- $\mathrm{PV}^{+}$, including cholecystokinin $\left(\mathrm{CCK}^{+}\right)$expressing inhibitory neurons predominate (Medalla et al., 2017). Indeed, here we found that the density of $\mathrm{PV}^{+} \mathrm{m}^{+}$and $\mathrm{PV}^{+} \mathrm{m}^{+}$expressing interneurons was greater in LPFC than in ACC. Thus, while studies to confirm the neurochemical identity of $\mathrm{m} 2^{+}$inhibitory axon terminals are ongoing, our previous work (Medalla et al., 2017) and current data suggest that non- $\mathrm{PV}^{+}$perisomatic inhibitory inputs are the likely predominant targets of $\mathrm{m}^{+}$mediated suppression in the ACC. Further, $\mathrm{m}^{+} \mathrm{VGAT}^{+}$inhibitory cartridges, presumably belonging to $\mathrm{PV}^{+}$chandelier cells (ChC) which target the axon-initial segment (AIS) of pyramidal neurons (Somogyi, 1977; Inan et al., 2013), were also more prevalent in the ACC, compared to the LPFC (Figure 10). In the ACC, 93\% of VGAT ${ }^{+}$ cartridges co-expressed $\mathrm{m}^{+}$, a substantially greater percentage compared to the $63 \%$ present in the LPFC. Further, we observed that these $\mathrm{VGAT}^{+}$cartridges were longer in the ACC, suggesting a greater number of release sites, compared to LPFC. Moreover, the density of $\mathrm{VGAT}^{+} \mathrm{m}^{+}$labeled boutons along strongly expressing $\mathrm{m} 2^{++}$cartridges was greater in ACC than in the LPFC. Taken together, our data suggest that $\mathrm{m} 2^{+}$modulation of proximal perisomatic and AIS inhibition of L3 pyramidal neurons is greater in ACC than LPFC. These differences in the morphology and neuromodulation of $\mathrm{VGAT}^{+}$cartridges on the AIS have important implications on action potential initiation (Lewis et al., 2011; Inan et al., 2013), excitability (Szabadics et al., 2006; Glickfeld et al., 2009; Woodruff et al., 2011), plasticity and temporal dynamics in these two prefrontal areas (Grubb et al., 2011; Kole and Stuart, 2012). Previous work has directly measured the length of AIS length in monkey LPFC and reported differences in length and inhibitory bouton density across development (Fish et al., 2013). In human schizophrenic patients, inhibitory cartridges in LPFC have been found to decrease in density (Woo et al., 1998; Rocco et al., 2017). To the best of our knowledge, this is the first time regional differences in $\mathrm{VGAT}^{+}$ cartridge lengths have been reported in the monkey prefrontal cortex, which has important implications on the dynamics of cognitive circuitry and its dysfunction in disease.

The current study also found regional differences in dendritic inhibition, presumably governed by distinct cell types. In contrast to $\mathrm{PV}^{+}$interneurons that are densest in LPFC L3, the $\mathrm{m}^{+} / \mathrm{m}^{+}$expressing $\mathrm{CB}^{+}$and $\mathrm{CR}^{+}$, mainly dendritic-targeting, interneuron subtypes (DeFelipe, 1997) are most prevalent in ACC L2. In the ACC, $\mathrm{VGAT}^{+}$proximal dendritic inputs, as well as, presumably distal $\mathrm{CB}^{+} \mathrm{VGAT}^{+}$axon terminals had a greater proportion colocalized with $\mathrm{m}^{+}$compared to LPFC (as summarized in Figure 10). While future immunolabeling and super-resolution or electron microscopy are needed to validate these compartment-specific synapses, our data suggest distinct suppression of GABA release from proximal and distal inhibitory synapses (Hajos et al., 1998; Salgado et al., 2007) that can lead to diverse temporal dynamics and synchrony across neuronal compartments in ACC and LPFC.

\section{Implications on Prefrontal Network Cholinergic Neuromodulation}

In primate LPFC, in vivo electrophysiological studies have found that $\mathrm{ACh}$, through muscarinic activation, increased firing rates and enhanced attentional modulation in broad and narrow spiking cells (Dasilva et al., 2019). However, $\mathrm{m} 1$ activation mainly suppressed delay-related activity in a heterogenous set of neurons in LPFC during a working memory task, with overstimulation of $\mathrm{m} 1$ resulting in disruption of rule representation (Vijayraghavan et al., 2018). These diverse ACh effects on cell-specific firing likely reflect how task-related activity emerges from concerted activation of distinct excitatory or inhibitory cell types, which cannot be reliably distinguished in vivo (Lee et al., 2021) and likely differ across cortical areas. Here, we present evidence that $\mathrm{m} 1$ receptors are widely expressed in both excitatory and inhibitory cell types in LPFC, providing the anatomical substrate for these diverse functional effects. However, while, indeed, excitatory neurons outnumber inhibitory neurons in 
ACC and LPFC, the proportion expressing $\mathrm{m} 1$ is lower for excitatory pyramidal neurons $(80-70 \%)$ compared to inhibitory neurons, with almost $100 \%$ expressing $\mathrm{m} 1$. The prevalence of $\mathrm{m} 1$ expression on inhibitory neurons in these two prefrontal areas is greater than the proportions previously observed in monkey visual areas (Disney et al., 2006; Disney and Aoki, 2008). Thus, our anatomical data predict that $\mathrm{m} 1$ overstimulation in ACC and LPFC can potentially alter excitatory:inhibitory neuronal activity ratio, and produce strong net inhibition (Vijayraghavan et al., 2018). Further, our current and previous data (Medalla et al., 2017) show that total inhibition is greater in ACC than LPFC, but this inhibition in ACC can be more robustly diminished via presynaptic $\mathrm{m} 2$ receptors. While future computational work is needed to understand the direct implications of these circuits, our data are consistent with the role of ACC signals in many flexible goal-directed behaviors (i.e., error- conflict- signaling and task switching) that require inhibition to be engaged or dis-engaged depending on the task at hand (Botvinick et al., 2004; Brown and Braver, 2008; Quilodran et al., 2008; Chudasama et al., 2013; Voloh et al., 2015; Kolling et al., 2016; Kawai et al., 2019; Kim and Sejnowski, 2021).

In the ACC, the inhibitory axon terminals with the most robust $\mathrm{m}^{+}$expression belong to non- $\mathrm{PV}^{+}$dendritic and perisomatic targeting cells, and AIS targeting ChC cells, all of which are thought to exhibit slow inhibitory synaptic kinetics (Figure 10; Nusser et al., 1996; Nyiri et al., 2001; Lewis et al., 2011; Tremblay et al., 2016). In rodents, $\mathrm{CCK}^{+}$, basket cells and $\mathrm{PV}^{+} \mathrm{ChC}$ synapses are thought to be associated with a2 GABAergic subunits (Nyiri et al., 2001; Klausberger et al., 2002; Rocco et al., 2017). In contrast, $\mathrm{PV}^{+}$basket cell synapses on somata are associated with the $\alpha 1$ GABAergic subunit with faster kinetics (Klausberger et al., 2002; Cardin et al., 2009). Further, in rhesus monkeys, $\mathrm{CB}$ dendritic-targeting inhibitory neurons (DeFelipe et al., 1989), unlike PV interneurons, are non-fast spiking (Zaitsev et al., 2005), characterized by long membrane time constants and action potential durations (Kawaguchi and Kubota, 1998; Zaitsev et al., 2005). Thus, our data suggest that ACh can reduce specifically slow inhibitory currents, to a greater degree in ACC than LPFC (Hajos et al., 1998; Salgado et al., 2007; Szabo et al., 2010). In contrast, the high density of $\mathrm{ml}^{+} \mathrm{PV}^{+}$neurons coupled with the low density of $\mathrm{m}^{+}$on perisomatic terminals on L3 pyramidal neurons in LPFC, suggests that ACh can increase firing of presumably fast-spiking $\mathrm{PV}^{+}$basket cells without concurrent downstream suppression of their GABAergic release (Figure 10). This hypothesis is consistent with recent physiological work in the rodent frontal cortex showing that carbachol increased excitatory drive and depolarized $\mathrm{L} 3 \mathrm{PV}^{+}$basket cells via $\mathrm{ml}^{+}$activation, but did not affect the activity of $\mathrm{PV}^{+} \mathrm{ChC}$ (Tikhonova et al., 2018).

Our data revealed that while $\sim 92-100 \%$ of all inhibitory interneurons examined expressed $\mathrm{m}^{+}$and thereby can be activated by $\mathrm{ACh}$, each subclass can be concurrently subject to specific $\mathrm{m}^{+}$mediated suppression at the level of their termination sites to influence network synchrony and information flow (Figure 10; Hajos et al., 1998; Salgado et al., 2007; Szabo et al., 2010; Colangelo et al., 2019). Previous work in rodents shows that coordinated perisomatic inhibition and depolarization of dendrites can govern theta activation and long-term potentiation in hippocampal CA1 (Kamondi et al., 1998; Bezaire et al., 2016). Muscarinic agonists can either drive theta or gamma activity depending on concerted activation of distinct inhibitory neurons and selective suppression of compartment-specific inhibitory synapses in the rodent cortex and hippocampus (Chapman and Lacaille, 1999; Levesque and Avoli, 2018). Given the important role of inhibitory synaptic kinetics on network oscillations (Kopell et al., 2010; Cardin, 2018) our data suggest that the greater capacity for ACh suppression of slow inhibition in ACC and potentiation of fast inhibition in LPFC can have a net effect of synchronizing fast oscillatory dynamics within and between the two areas (Medalla et al., 2017). This hypothesis is consistent with in vivo work in monkeys showing the role of gamma coordination within and between ACC and LPFC in cognitive processing, especially during behavioral shifts and error trials (Quilodran et al., 2008; Rothe et al., 2011). More detailed structural, physiological, and computational experiments are currently underway to examine the cholinergic modulation of specific GABAergic cell types, the contribution of distinct muscarinic, as well as, nicotinic receptors, and the downstream effects on network dynamics.

In summary, the data presented here shows the laminarand cell-type-specific expression of $\mathrm{m} 1$ and $\mathrm{m} 2$ muscarinic receptors within ACC and LPFC that may underlie distinct cholinergic modulation in these prefrontal areas. We found laminar specificity in $\mathrm{m}^{+}$dendritic expression, and in $\mathrm{m} 2^{+}$presynaptic localization on cortico-cortical $\left(\mathrm{VGLUT1}^{+}\right.$) and sub-cortical inputs $\left(\mathrm{VGLUT}^{+}\right)$, suggesting differential cholinergic modulation of "top-down" vs. "bottom-up" inputs in the two areas (Corbetta and Shulman, 2002; Disney et al., 2006). Further, our data suggest greater compartment-specific $\mathrm{m} 2^{+}$suppression of GABA-release in ACC L3 pyramidal neurons than in LPFC (Hajos et al., 1998; Salgado et al., 2007; Szabo et al., 2010). The anatomical localization of muscarinic receptors on distinct ACC and LPFC micro-circuits shown here sheds light on the functional outcomes of prefrontal cholinergic modulation of excitatory and inhibitory balance in normal behavior and its disruption in neuropsychiatric and neurological conditions.

\section{DATA AVAILABILITY STATEMENT}

The original contributions presented in the study are included in the article, further inquiries can be directed to the corresponding author.

\section{ETHICS STATEMENT}

The animal study was reviewed and approved by Boston University Institutional Animal Care and Use Committee.

\section{AUTHOR CONTRIBUTIONS}

AT designed and performed experiments, data gathering, and analysis. MM conceptualized and designed the study 
and experiments. AT and MM wrote the manuscript. All authors contributed to the article and approved the submitted version.

\section{FUNDING}

This work was supported by the National Institutes of Health (NIH)/National Institute of Mental Health (NIMH) K99/R00MH101234, R01 MH116008 (PI: MM), and National Institute of Aging (NIA) RF1-AG043640 (PI: D. L. Rosene).

\section{REFERENCES}

Amatrudo, J. M., Weaver, C. M., Crimins, J. L., Hof, P. R., Rosene, D. L., and Luebke, J. I. (2012). Influence of highly distinctive structural properties on the excitability of pyramidal neurons in monkey visual and prefrontal cortices. J. Neurosci. 32, 13644-13660. doi: 10.1523/JNEUROSCI.2581-12.2012

Barbas, H. (1986). Pattern in the laminar origin of corticocortical connections. J. Comp. Neurol. 252, 415-422. doi: 10.1002/cne.902520310

Barbas, H. (2000). Connections underlying the synthesis of cognition, memory and emotion in primate prefrontal cortices. Brain Res. Bull. 52, 319-330. doi: 10.1016/s0361-9230(99)00245-2

Barbas, H., and Garcia-Cabezas, M. A. (2016). How the prefrontal executive got its stripes. Curr. Opin. Neurobiol. 40, 125-134. doi: 10.1016/j.conb.2016.07.003

Barbas, H., and Pandya, D. N. (1989). Architecture and intrinsic connections of the prefrontal cortex in the rhesus monkey. J. Comp. Neurol. 286, 353-375. doi: 10.1002/cne.902860306

Barbas, H., Wang, J., Joyce, M. K. P., and Garcia-Cabezas, M. A. (2018). Pathway mechanism for excitatory and inhibitory control in working memory. J. Neurophysiol. 120, 2659-2678. doi: 10.1152/jn.00936.2017

Barbas, H., and Zikopoulos, B. (2007). The prefrontal cortex and flexible behavior. Neuroscientist 13, 532-545. doi: 10.1177/1073858407301369

Bartos, M., and Elgueta, C. (2012). Functional characteristics of parvalbuminand cholecystokinin-expressing basket cells. J. Physiol. 590, 669-681. doi: 10.1113/jphysiol.2011.226175

Bartus, R. T., and Johnson, H. R. (1976). Short-term memory in the rhesus monkey: disruption from the anti-cholinergic scopolamine. Pharmacol. Biochem. Behav. 5, 39-46. doi: 10.1016/0091-3057(76)90286-0

Bezaire, M. J., Raikov, I., Burk, K., Vyas, D., and Soltesz, I. (2016). Interneuronal mechanisms of hippocampal theta oscillations in a full-scale model of the rodent CA1 circuit. eLife 5:e18566. doi: 10.7554/eLife. 18566

Botvinick, M. M., Cohen, J. D., and Carter, C. S. (2004). Conflict monitoring and anterior cingulate cortex: an update. Trends Cogn. Sci. 8, 539-546. doi: $10.1016 /$ j.tics.2004.10.003

Broks, P., Preston, G. C., Traub, M., Poppleton, P., Ward, C., and Stahl, S. M. (1988). Modelling dementia: effects of scopolamine on memory and attention. Neuropsychologia 26, 685-700. doi: 10.1016/0028-3932(88) 90004-8

Brown, J. W., and Braver, T. S. (2008). A computational model of risk, conflict and individual difference effects in the anterior cingulate cortex. Brain Res. 1202, 99-108. doi: 10.1016/j.brainres.2007.06.080

Bussiere, T., Giannakopoulos, P., Bouras, C., Perl, D. P., Morrison, J. H., and Hof, P. R. (2003). Progressive degeneration of nonphosphorylated neurofilament protein-enriched pyramidal neurons predicts cognitive impairment in Alzheimer's disease: stereologic analysis of prefrontal cortex area 9. J. Comp. Neurol. 463, 281-302. doi: 10.1002/cne.10760

Caceres, A., Banker, G., Steward, O., Binder, L., and Payne, M. (1984). MAP2 is localized to the dendrites of hippocampal neurons which develop in culture. Brain Res. 315, 314-318. doi: 10.1016/0165-3806(84)90167-6

Calderazzo, S. M., Busch, S. E., Moore, T. L., Rosene, D. L., and Medalla, M. (2021). Distribution and overlap of entorhinal, premotor and amygdalar connections in the monkey anterior cingulate cortex. J. Comp. Neurol. 529, 885-904. doi: 10.1002/cne.24986

Campbell, M. J., and Morrison, J. H. (1989). Monoclonal antibody to neurofilament protein (SMI-32) labels a subpopulation of pyramidal neurons

\section{ACKNOWLEDGMENTS}

We thank Dr. Douglas Rosene for providing the monkey tissue used to complete this study; Dr. Tara Moore for assistance with animal procedures and tissue harvesting; Dr. Farzad Mortazavi, Penny Schultz, Karen Slater, Dr. Ajay Uprety, Karen Bottenfield, and Samantha Calderazzo for help with brain cutting; Mollie Sherman, Marianna Tsolias, Chromewell Mojica, and Joy Yang for help with data acquisition; Dr. Jennifer Luebke and Wayne Chang for helpful comments and discussions on the manuscript.

in the human and monkey neocortex. J. Comp. Neurol. 282, 191-205. doi: 10.1002/cne.902820204

Cardin, J. A. (2018). Inhibitory interneurons regulate temporal precision and correlations in cortical circuits. Trends Neurosci. 41, 689-700. doi: 10.1016/j. tins.2018.07.015

Cardin, J. A., Carlen, M., Meletis, K., Knoblich, U., Zhang, F., Deisseroth, K., et al. (2009). Driving fast-spiking cells induces gamma rhythm and controls sensory responses. Nature 459, 663-667. doi: 10.1038/nature08002

Carr, D. B., and Surmeier, D. J. (2007). M1 muscarinic receptor modulation of Kir2 channels enhances temporal summation of excitatory synaptic potentials in prefrontal cortex pyramidal neurons. J. Neurophysiol. 97, 3432-3438. doi: 10.1152 /jn.00828.2006

Chapman, C. A., and Lacaille, J. C. (1999). Cholinergic induction of thetafrequency oscillations in hippocampal inhibitory interneurons and pacing of pyramidal cell firing. J. Neurosci. 19, 8637-8645. doi: 10.1523/JNEUROSCI.1919-08637.1999

Chaudhry, F. A., Reimer, R. J., Bellocchio, E. E., Danbolt, N. C., Osen, K. K., Edwards, R. H., et al. (1998). The vesicular GABA transporter, VGAT, localizes to synaptic vesicles in sets of glycinergic as well as GABAergic neurons. J. Neurosci. 18, 9733-9750. doi: 10.1523/JNEUROSCI. 18-23-09733.1998

Chudasama, Y., Daniels, T. E., Gorrin, D. P., Rhodes, S. E., Rudebeck, P. H., and Murray, E. A. (2013). The role of the anterior cingulate cortex in choices based on reward value and reward contingency. Cereb. Cortex 23, 2884-2898. doi: 10.1093/cercor/bhs266

Colangelo, C., Shichkova, P., Keller, D., Markram, H., and Ramaswamy, S. (2019). Cellular, synaptic and network effects of acetylcholine in the neocortex. Front. Neural Circuits 13:24. doi: 10.3389/fncir.2019.00024

Constantinidis, C., Franowicz, M. N., and Goldman-Rakic, P. S. (2001). Coding specificity in cortical microcircuits: a multiple-electrode analysis of primate prefrontal cortex. J. Neurosci. 21, 3646-3655. doi: 10.1523/JNEUROSCI.21-1003646.2001

Coppola, J. J., Ward, N. J., Jadi, M. P., and Disney, A. A. (2016). Modulatory compartments in cortex and local regulation of cholinergic tone. J. Physiol. Paris 110, 3-9. doi: 10.1016/j.jphysparis.2016.08.001

Corbetta, M., and Shulman, G. L. (2002). Control of goal-directed and stimulus-driven attention in the brain. Nat. Rev. Neurosci. 3, 201-215. doi: 10.1038/nrn755

Croxson, P. L., Kyriazis, D. A., and Baxter, M. G. (2011). Cholinergic modulation of a specific memory function of prefrontal cortex. Nat. Neurosci. 14, 1510-1512. doi: 10.1038/nn.2971

Dasilva, M., Brandt, C., Gotthardt, S., Gieselmann, M. A., Distler, C., and Thiele, A. (2019). Cell class-specific modulation of attentional signals by acetylcholine in macaque frontal eye field. Proc. Natl. Acad. Sci. U S A 116, 20180-20189. doi: 10.1073/pnas.1905413116

DeFelipe, J. (1997). Types of neurons, synaptic connections and chemical characteristics of cells immunoreactive for calbindin-D28K, parvalbumin and calretinin in the neocortex. J. Chem. Neuroanat. 14, 1-19. doi: 10.1016/s08910618(97)10013-8

DeFelipe, J., Gonzalez-Albo, M. C., Del Rio, M. R., and Elston, G. N. (1999). Distribution and patterns of connectivity of interneurons containing calbindin, calretinin and parvalbumin in visual areas of the occipital and temporal lobes of the macaque monkey. J. Comp. Neurol. 412, 515-526. doi: 10.1002/(sici)10969861(19990927)412:3<515::aid-cne10>3.0.co;2-1 
DeFelipe, J., Hendry, S. H., and Jones, E. G. (1989). Visualization of chandelier cell axons by parvalbumin immunoreactivity in monkey cerebral cortex. Proc. Natl. Acad. Sci. U S A 86, 2093-2097. doi: 10.1073/pnas.86.6.2093

del Rio, M. R., and DeFelipe, J. (1997). Synaptic connections of calretininimmunoreactive neurons in the human neocortex. J. Neurosci. 17, 5143-5154. doi: 10.1523/JNEUROSCI.17-13-05143.1997

Dennis, S. H., Pasqui, F., Colvin, E. M., Sanger, H., Mogg, A. J., Felder, C. C., et al. (2016). Activation of muscarinic M1 acetylcholine receptors induces long-term potentiation in the hippocampus. Cereb. Cortex 26, 414-426. doi: $10.1093 /$ cercor/bhv227

Descarries, L., and Mechawar, N. (2000). Ultrastructural evidence for diffuse transmission by monoamine and acetylcholine neurons of the central nervous system. Prog. Brain Res. 125, 27-47. doi: 10.1016/S0079-6123(00)25005-X

Deutsch, J. A. (1971). The cholinergic synapse and the site of memory. Science 174, 788-794. doi: 10.1126/science.174.4011.788

Devinsky, O., Morrell, M. J., and Vogt, B. A. (1995). Contributions of anterior cingulate cortex to behaviour. Brain 118, 279-306. doi: 10.1093/brain/ 118.1.279

Disney, A. A., and Aoki, C. (2008). Muscarinic acetylcholine receptors in macaque V1 are most frequently expressed by parvalbumin-immunoreactive neurons. J. Comp. Neurol. 507, 1748-1762. doi: 10.1002/cne.21616

Disney, A. A., Domakonda, K. V., and Aoki, C. (2006). Differential expression of muscarinic acetylcholine receptors across excitatory and inhibitory cells in visual cortical areas V1 and V2 of the macaque monkey. J. Comp. Neurol. 499, 49-63. doi: 10.1002/cne.21096

Disney, A. A., and Higley, M. J. (2020). Diverse spatiotemporal scales of cholinergic signaling in the neocortex. J. Neurosci. 40, 720-725. doi: 10.1523/JNEUROSCI.1306-19.2019

Dombrowski, S. M., Hilgetag, C. C., and Barbas, H. (2001). Quantitative architecture distinguishes prefrontal cortical systems in the rhesus monkey. Cereb. Cortex 11, 975-988. doi: 10.1093/cercor/11.10.975

Drachman, D., and Leavitt, J. (1974). Human memory and the cholinergic system. a relationship to aging. Arch. Neurol. 30, 113-121. doi: 10.1001/archneur.1974. 00490320001001

Dumas, T. C., Powers, E. C., Tarapore, P. E., and Sapolsky, R. M. (2004). Overexpression of calbindin $\mathrm{D}(28 \mathrm{k})$ in dentate gyrus granule cells alters mossy fiber presynaptic function and impairs hippocampal-dependent memory. Hippocampus 14, 701-709. doi: 10.1002/hipo.10210

Estrada, L. I., Robinson, A. A., Amaral, A. C., Giannaris, E. L., Heyworth, N. C., Mortazavi, F., et al. (2017). Evaluation of long-term cryostorage of brain tissue sections for quantitative histochemistry. J. Histochem. Cytochem. 65, 153-171. doi: 10.1369/0022155416686934

Everitt, B. J., and Robbins, T. W. (1997). Central cholinergic systems and cognition. Annu. Rev. Psychol. 48, 649-684. doi: 10.1146/annurev.psych.48.1. 649

Fiala, J. C., and Harris, K. M. (2001). Extending unbiased stereology of brain ultrastructure to three-dimensional volumes. J. Am. Med. Inform. Assoc. 8, 1-16. doi: 10.1136/jamia.2001.0080001

Fish, K. N., Hoftman, G. D., Sheikh, W., Kitchens, M., and Lewis, D. A. (2013). Parvalbumin-containing chandelier and basket cell boutons have distinctive modes of maturation in monkey prefrontal cortex. J. Neurosci. 33, 8352-8358. doi: 10.1523/JNEUROSCI.0306-13.2013

Foster, D. J., Bryant, Z. K., and Conn, P. J. (2021). Targeting muscarinic receptors to treat schizophrenia. Behav. Brain Res. 405:113201. doi: 10.1016/j.bbr.2021. 113201

Fremeau, R. T., Jr., Voglmaier, S., Seal, R. P., and Edwards, R. H. (2004). VGLUTs define subsets of excitatory neurons and suggest novel roles for glutamate. Trends Neurosci. 27, 98-103. doi: 10.1016/j.tins.2003.11.005

Freund, T. F., and Katona, I. (2007). Perisomatic inhibition. Neuron 56, 33-42. doi: 10.1016/j.neuron.2007.09.012

Gabbott, P. L. (2016). "Subpial fan cell" - a class of calretinin neuron in layer 1 of adult monkey prefrontal cortex. Front. Neuroanat. 10:28. doi: 10.3389/fnana. 2016.00028

Gabbott, P. L., and Bacon, S. J. (1997). Vasoactive intestinal polypeptide containing neurones in monkey medial prefrontal cortex (mPFC): colocalisation with calretinin. Brain Res. 744, 179-184. doi: 10.1016/s0006-8993(96)01232-2

Ghashghaei, H. T., and Barbas, H. (2001). Neural interaction between the basal forebrain and functionally distinct prefrontal cortices in the rhesus monkey. Neuroscience 103, 593-614. doi: 10.1016/s0306-4522(00) 00585-6

Glickfeld, L. L., Roberts, J. D., Somogyi, P., and Scanziani, M. (2009). Interneurons hyperpolarize pyramidal cells along their entire somatodendritic axis. Nat. Neurosci. 12, 21-23. doi: 10.1038/nn.2230

Gonzalez-Burgos, G., Barrionuevo, G., and Lewis, D. A. (2000). Horizontal synaptic connections in monkey prefrontal cortex: an in vitro electrophysiological study. Cereb. Cortex 10, 82-92. doi: 10.1093/cercor/ 10.1 .82

Groleau, M., Kang, J. I., Huppe-Gourgues, F., and Vaucher, E. (2015). Distribution and effects of the muscarinic receptor subtypes in the primary visual cortex. Front. Synaptic Neurosci. 7:10. doi: 10.3389/fnsyn.2015.00010

Grubb, M. S., Shu, Y., Kuba, H., Rasband, M. N., Wimmer, V. C., and Bender, K. J. (2011). Short- and long-term plasticity at the axon initial segment. J. Neurosci. 31, 16049-16055. doi: 10.1523/JNEUROSCI.4064-11.2011

Hackett, T. A., Takahata, T., and Balaram, P. (2011). VGLUT1 and VGLUT2 mRNA expression in the primate auditory pathway. Hear Res. 274, 129-141. doi: 10.1016/j.heares.2010.11.001

Hajos, N., Papp, E. C., Acsady, L., Levey, A. I., and Freund, T. F. (1998). Distinct interneuron types express $\mathrm{m} 2$ muscarinic receptor immunoreactivity on their dendrites or axon terminals in the hippocampus. Neuroscience 82, 355-376. doi: $10.3389 /$ fnins.2021.752594

Hampel, H., Mesulam, M. M., Cuello, A. C., Farlow, M. R., Giacobini, E., Grossberg, G. T., et al. (2018). The cholinergic system in the pathophysiology and treatment of Alzheimer's disease. Brain 141, 1917-1933. doi: 10.1093/brain/awy132

Hasselmo, M. E., and Bower, J. M. (1992). Cholinergic suppression specific to intrinsic not afferent fiber synapses in rat piriform (olfactory) cortex. J. Neurophysiol. 67, 1222-1229. doi: 10.1152/jn.1992.67.5.1222

Hasselmo, M. E., and Sarter, M. (2011). Modes and models of forebrain cholinergic neuromodulation of cognition. Neuropsychopharmacology 36, 52-73. doi: 10.1038/npp.2010.104

Herrero, J. L., Gieselmann, M. A., and Thiele, A. (2017). Muscarinic and nicotinic contribution to contrast sensitivity of macaque area V1 neurons. Front. Neural Circuits 11:106. doi: 10.3389/fncir.2017.00106

Herrero, J. L., Roberts, M. J., Delicato, L. S., Gieselmann, M. A., Dayan, P., and Thiele, A. (2008). Acetylcholine contributes through muscarinic receptors to attentional modulation in V1. Nature 454, 1110-1114. doi: $10.1038 /$ nature 07141

Hof, P. R., and Nimchinsky, E. A. (1992). Regional distribution of neurofilament and calcium-binding proteins in the cingulate cortex of the macaque monkey. Cereb. Cortex 2, 456-467. doi: 10.1093/cercor/2.6.456

Hur, E. E., and Zaborszky, L. (2005). Vglut2 afferents to the medial prefrontal and primary somatosensory cortices: a combined retrograde tracing in situ hybridization study [corrected]. J. Comp. Neurol. 483, 351-373. doi: 10.1002/cne.20444

Inan, M., Blazquez-Llorca, L., Merchan-Perez, A., Anderson, S. A., DeFelipe, J., and Yuste, R. (2013). Dense and overlapping innervation of pyramidal neurons by chandelier cells. J. Neurosci. 33, 1907-1914. doi: 10.1523/JNEUROSCI.404912.2013

Jones, E. G. (2009). Synchrony in the interconnected circuitry of the thalamus and cerebral cortex. Ann. N Y Acad. Sci. 1157, 10-23. doi: 10.1111/j.1749-6632.2009. 04534.x

Kamondi, A., Acsady, L., Wang, X. J., and Buzsaki, G. (1998). Theta oscillations in somata and dendrites of hippocampal pyramidal cells in vivo: activitydependent phase-precession of action potentials. Hippocampus 8, 244-261. doi: 10.1002/(SICI)1098-1063(1998)8:3<244::AID-HIPO7>3.0.CO;2-J

Kawaguchi, Y., and Kubota, Y. (1998). Neurochemical features and synaptic connections of large physiologically-identified GABAergic cells in the rat frontal cortex. Neuroscience 85, 677-701. doi: 10.1016/s0306-4522(97)00685-4

Kawai, T., Yamada, H., Sato, N., Takada, M., and Matsumoto, M. (2019). Preferential representation of past outcome information and future choice behavior by putative inhibitory interneurons rather than putative pyramidal neurons in the primate dorsal anterior cingulate cortex. Cereb. Cortex 29, 2339-2352. doi: 10.1093/cercor/bhy103

Kim, R., and Sejnowski, T. J. (2021). Strong inhibitory signaling underlies stable temporal dynamics and working memory in spiking neural networks. Nat. Neurosci. 24, 129-139. doi: 10.1038/s41593-020-00753-w 
Kimura, F., and Baughman, R. W. (1997). Distinct muscarinic receptor subtypes suppress excitatory and inhibitory synaptic responses in cortical neurons. J. Neurophysiol. 77, 709-716. doi: 10.1152/jn.1997.77.2.709

Klausberger, T., Roberts, J. D., and Somogyi, P. (2002). Cell type- and inputspecific differences in the number and subtypes of synaptic GABA(A) receptors in the hippocampus. J. Neurosci. 22, 2513-2521. doi: 10.1523/JNEUROSCI.2207-02513.2002

Kole, M. H., and Stuart, G. J. (2012). Signal processing in the axon initial segment. Neuron 73, 235-247. doi: 10.1016/j.neuron.2012.01.007

Kolling, N., Wittmann, M. K., Behrens, T. E., Boorman, E. D., Mars, R. B., and Rushworth, M. F. (2016). Value, search, persistence and model updating in anterior cingulate cortex. Nat. Neurosci. 19, 1280-1285. doi: 10.1038/nn.4382

Kondo, H., Tanaka, K., Hashikawa, T., and Jones, E. G. (1999). Neurochemical gradients along monkey sensory cortical pathways: calbindin-immunoreactive pyramidal neurons in layers II and III. Eur. J. Neurosci. 11, 4197-4203. doi: 10.1046/j.1460-9568.1999.00844.x

Kopell, N., Kramer, M. A., Malerba, P., and Whittington, M. A. (2010). Are different rhythms good for different functions. Front. Hum. Neurosci. 4:187. doi: $10.3389 /$ fnhum.2010.00187

Kubota, Y., Karube, F., Nomura, M., and Kawaguchi, Y. (2016). The diversity of cortical inhibitory synapses. Front. Neural Circuits 10:27. doi: 10.3389/fncir. 2016.00027

LeBlang, C. J., Medalla, M., Nicoletti, N. W., Hays, E. C., Zhao, J., Shattuck, J., et al. (2020). Reduction of the RNA binding protein TIAl exacerbates neuroinflammation in tauopathy. Front. Neurosci. 14:285. doi: 10.3389/fnins. 2020.00285

Lee, E. K., Balasubramanian, H., Tsolias, A., Anakwe, S. U., Medalla, M., Shenoy, K. V., et al. (2021). Non-linear dimensionality reduction on extracellular waveforms reveals cell type diversity in premotor cortex. eLife 10:e67490. doi: 10.7554/eLife.67490

Levesque, M., and Avoli, M. (2018). Carbachol-Induced theta-like oscillations in the rodent brain limbic system: underlying mechanisms and significance. Neurosci. Biobehav. Rev. 95, 406-420. doi: 10.1016/j.neubiorev.2018. 10.018

Levey, A. I. (1996). Muscarinic acetylcholine receptor expression in memory circuits: implications for treatment of Alzheimer disease. Proc. Natl. Acad. Sci. U S A 93, 13541-13546. doi: 10.1073/pnas.93.24.13541

Levy, R., and Goldman-Rakic, P. S. (2000). Segregation of working memory functions within the dorsolateral prefrontal cortex. Exp. Brain Res. 133, 23-32. doi: $10.1007 /$ s002210000397

Lewis, D. A., Fish, K. N., Arion, D., and Gonzalez-Burgos, G. (2011). Perisomatic inhibition and cortical circuit dysfunction in schizophrenia. Curr. Opin. Neurobiol. 21, 866-872. doi: 10.1016/j.conb.2011.05.013

Li, J. T., Xie, X. M., Yu, J. Y., Sun, Y. X., Liao, X. M., Wang, X. X., et al. (2017). Suppressed calbindin levels in hippocampal excitatory neurons mediate stressinduced memory loss. Cell Rep. 21, 891-900. doi: 10.1016/j.celrep.2017.10.006

Major, A. J., Vijayraghavan, S., and Everling, S. (2015). Muscarinic attenuation of mnemonic rule representation in macaque dorsolateral prefrontal cortex during a pro- and anti-saccade task. J. Neurosci. 35, 16064-16076. doi: 10.1523/JNEUROSCI.2454-15.2015

Marino, M. J., Rouse, S. T., Levey, A. I., Potter, L. T., and Conn, P. J. (1998). Activation of the genetically defined $\mathrm{ml}$ muscarinic receptor potentiates $\mathrm{N}$ methyl-D-aspartate (NMDA) receptor currents in hippocampal pyramidal cells. Proc. Natl. Acad. Sci. U S A 95, 11465-11470. doi: 10.1073/pnas.95.19. 11465

Markram, H., and Segal, M. (1990). Acetylcholine potentiates responses to $\mathrm{N}$-methyl-D-aspartate in the rat hippocampus. Neurosci. Lett. 113, 62-65. doi: 10.1016/0304-3940(90)90495-u

Markram, H., Toledo-Rodriguez, M., Wang, Y., Gupta, A., Silberberg, G., and $\mathrm{Wu}, \mathrm{C} .(2004)$. Interneurons of the neocortical inhibitory system. Nat. Rev. Neurosci. 5, 793-807. doi: 10.1038/nrn1519

Mash, D. C., White, W. F., and Mesulam, M. M. (1988). Distribution of muscarinic receptor subtypes within architectonic subregions of the primate cerebral cortex. J. Comp. Neurol. 278, 265-274. doi: 10.1002/cne.902780209

Medalla, M., and Barbas, H. (2012). The anterior cingulate cortex may enhance inhibition of lateral prefrontal cortex via $\mathrm{m} 2$ cholinergic receptors at dual synaptic sites. J. Neurosci. 32, 15611-15625. doi: 10.1523/JNEUROSCI.2339-12. 2012
Medalla, M., Gilman, J. P., Wang, J. Y., and Luebke, J. I. (2017). Strength and diversity of inhibitory signaling differentiates primate anterior cingulate from lateral prefrontal cortex. J. Neurosci. 37, 4717-4734. doi: 10.1523/JNEUROSCI. 3757-16.2017

Medalla, M., and Luebke, J. I. (2015). Diversity of glutamatergic synaptic strength in lateral prefrontal versus primary visual cortices in the rhesus monkey. J. Neurosci. 35, 112-127. doi: 10.1523/JNEUROSCI.3426-14.2015

Mesulam, M. M., Hersh, L. B., Mash, D. C., and Geula, C. (1992). Differential cholinergic innervation within functional subdivisions of the human cerebral cortex: a choline acetyltransferase study. J. Comp. Neurol. 318, 316-328. doi: $10.1002 /$ cne. 903180308

Mesulam, M. M., Rosen, A. D., and Mufson, E. J. (1984). Regional variations in cortical cholinergic innervation: chemoarchitectonics of acetylcholinesterasecontaining fibers in the macaque brain. Brain Res. 311, 245-258. doi: 10.1016/0006-8993(84)90087-8

Miller, E. K., and Cohen, J. D. (2001). An integrative theory of prefrontal cortex function. Annu. Rev. Neurosci. 24, 167-202. doi: 10.1146/annurev.neuro.24.1. 167

Molinari, S., Battini, R., Ferrari, S., Pozzi, L., Killcross, A. S., Robbins, T. W., et al. (1996). Deficits in memory and hippocampal long-term potentiation in mice with reduced calbindin D28K expression. Proc. Natl. Acad. Sci. U S A 93, 8028-8033. doi: $10.1073 /$ pnas.93.15.8028

Moran, S. P., Maksymetz, J., and Conn, P. J. (2019). Targeting muscarinic acetylcholine receptors for the treatment of psychiatric and neurological disorders. Trends Pharmacol. Sci. 40, 1006-1020. doi: 10.1016/j.tips.2019. 10.007

Morrison, J. H., and Hof, P. R. (2002). Selective vulnerability of corticocortical and hippocampal circuits in aging and Alzheimer's disease. Prog. Brain Res. 136, 467-486. doi: 10.1016/s0079-6123(02)36039-4

Moss, D. E. (2020). Improving anti-neurodegenerative benefits of acetylcholinesterase inhibitors in Alzheimer's disease: are irreversible inhibitors the future. Int. J. Mol. Sci. 21:3438. doi: 10.3390/ijms21103438

Mrzljak, L., Levey, A. I., Belcher, S., and Goldman-Rakic, P. S. (1998). Localization of the $\mathrm{m} 2$ muscarinic acetylcholine receptor protein and mRNA in cortical neurons of the normal and cholinergically deafferented rhesus monkey. J. Comp. Neurol. 390, 112-132.

Mrzljak, L., Levey, A. I., and Goldman-Rakic, P. S. (1993). Association of $\mathrm{m} 1$ and $\mathrm{m} 2$ muscarinic receptor proteins with asymmetric synapses in the primate cerebral cortex: morphological evidence for cholinergic modulation of excitatory neurotransmission. Proc. Natl. Acad. Sci. U S A 90, 5194-5198. doi: $10.1073 /$ pnas.90.11.5194

Mrzljak, L., Pappy, M., Leranth, C., and Goldman-Rakic, P. S. (1995). Cholinergic synaptic circuitry in the macaque prefrontal cortex. J. Comp. Neurol. 357, 603-617. doi: 10.1002/cne.903570409

Nusser, Z., Sieghart, W., Benke, D., Fritschy, J. M., and Somogyi, P. (1996). Differential synaptic localization of two major gamma-aminobutyric acid type a receptor alpha subunits on hippocampal pyramidal cells. Proc. Natl. Acad. Sci. U S A 93, 11939-11944. doi: 10.1073/pnas.93.21.11939

Nyiri, G., Freund, T. F., and Somogyi, P. (2001). Input-dependent synaptic targeting of alpha-subunit-containing GABA(A) receptors in synapses of hippocampal pyramidal cells of the rat. Eur. J. Neurosci. 13, 428-442. doi: 10.1046/j.1460-9568.2001.01407.x

Obermayer, J., Verhoog, M. B., Luchicchi, A., and Mansvelder, H. D. (2017). Cholinergic modulation of cortical microcircuits is layer-specific: evidence from rodent, monkey and human brain. Front. Neural Circuits 11:100. doi: 10.3389/fncir.2017.00100

Parikh, V., Kozak, R., Martinez, V., and Sarter, M. (2007). Prefrontal acetylcholine release controls cue detection on multiple timescales. Neuron 56, 141-154. doi: 10.1016/j.neuron.2007.08.025

Peters, A., and Sethares, C. (1991). Organization of pyramidal neurons in area 17 of monkey visual cortex. J. Comp. Neurol. 306, 1-23. doi: 10.1002/cne.9030 60102

Picciotto, M. R., Higley, M. J., and Mineur, Y. S. (2012). Acetylcholine as a neuromodulator: cholinergic signaling shapes nervous system function and behavior. Neuron 76, 116-129. doi: 10.1016/j.neuron.2012.08.036

Quilodran, R., Rothe, M., and Procyk, E. (2008). Behavioral shifts and action valuation in the anterior cingulate cortex. Neuron 57, 314-325. doi: 10.1016/j. neuron.2007.11.031 
Rocco, B. R., DeDionisio, A. M., Lewis, D. A., and Fish, K. N. (2017). Alterations in a unique class of cortical chandelier cell axon cartridges in schizophrenia. Biol. Psychiatry 82, 40-48. doi: 10.1016/j.biopsych.2016.09.018

Rocco, B. R., Sweet, R. A., Lewis, D. A., and Fish, K. N. (2016). GABA-synthesizing enzymes in calbindin and calretinin neurons in monkey prefrontal cortex. Cereb. Cortex 26, 2191-2204. doi: 10.1093/cercor/bhv051

Rogers, J. H. (1992). Immunohistochemical markers in rat cortex: co-localization of calretinin and calbindin-D28k with neuropeptides and GABA. Brain Res. 587, 147-157. doi: 10.1016/0006-8993(92)91439-1

Roland, P. E. (2002). Dynamic depolarization fields in the cerebral cortex. Trends Neurosci. 25, 183-190. doi: 10.1016/s0166-2236(00)02125-1

Rosene, D. L., Roy, N. J., and Davis, B. J. (1986). A cryoprotection method that facilitates cutting frozen sections of whole monkey brains for histological and histochemical processing without freezing artifact. J. Histochem. Cytochem. 34, 1301-1315. doi: 10.1177/34.10.3745909

Rothe, M., Quilodran, R., Sallet, J., and Procyk, E. (2011). Coordination of high gamma activity in anterior cingulate and lateral prefrontal cortical areas during adaptation. J. Neurosci. 31, 11110-11117. doi: 10.1523/JNEUROSCI.1016-11. 2011

Rushworth, M. F., Noonan, M. P., Boorman, E. D., Walton, M. E., and Behrens, T. E. (2011). Frontal cortex and reward-guided learning and decisionmaking. Neuron 70, 1054-1069. doi: 10.1016/j.neuron.2011.05.014

Salgado, H., Bellay, T., Nichols, J. A., Bose, M., Martinolich, L., Perrotti, L., et al. (2007). Muscarinic M2 and M1 receptors reduce GABA release by $\mathrm{Ca} 2+$ channel modulation through activation of PI3K/Ca2 + -independent and PLC/Ca2+ -dependent PKC. J. Neurophysiol. 98, 952-965. doi: 10.1152/jn. 00060.2007

Sarter, M., Parikh, V., and Howe, W. M. (2009). Phasic acetylcholine release and the volume transmission hypothesis: time to move on. Nat. Rev. Neurosci. 10, 383-390. doi: 10.1038/nrn2635

Schmitz, C., and Hof, P. R. (2005). Design-based stereology in neuroscience. Neuroscience 130, 813-831. doi: 10.1016/j.neuroscience.2004.08.050

Schneider, C. A., Rasband, W. S., and Eliceiri, K. W. (2012). NIH Image to ImageJ: 25 years of image analysis. Nat. Methods 9, 671-675. doi: 10.1038/nmeth.2089

Schuman, B., Machold, R. P., Hashikawa, Y., Fuzik, J., Fishell, G. J., and Rudy, B. (2019). Four unique interneuron populations reside in neocortical layer 1. J. Neurosci. 39, 125-139. doi: 10.1523/JNEUROSCI.1613-18.2018

Schindelin, J., Arganda-Carreras, I., Frise, E., Kaynig, V., Longair, M., Pietzsch, T., et al. (2012). Fiji: an open-source platform for biological-image analysis. Nat. Methods. 9, 676-682. doi: 10.1038/nmeth.2019

Seress, L., Gulyas, A. I., and Freund, T. F. (1991). Parvalbumin- and calbindin D28k-immunoreactive neurons in the hippocampal formation of the macaque monkey. J. Comp. Neurol. 313, 162-177. doi: 10.1002/cne.903130112

Somogyi, P. (1977). A specific "axo-axonal" interneuron in the visual cortex of the rat. Brain Res. 136, 345-350. doi: 10.1016/0006-8993(77)90808-3

Spruston, N. (2008). Pyramidal neurons: dendritic structure and synaptic integration. Nat. Rev. Neurosci. 9, 206-221. doi: 10.1038/nrn2286

Stauffer, W., Sheng, H., and Lim, H. N. (2018). EzColocalization: an ImageJ plugin for visualizing and measuring colocalization in cells and organisms. Sci. Rep. 8:15764. doi: 10.1038/s41598-018-33592-8

Szabadics, J., Varga, C., Molnar, G., Olah, S., Barzo, P., and Tamas, G. (2006). Excitatory effect of GABAergic axo-axonic cells in cortical microcircuits. Science 311, 233-235. doi: 10.1126/science. 1121325

Szabo, G. G., Holderith, N., Gulyas, A. I., Freund, T. F., and Hajos, N. (2010). Distinct synaptic properties of perisomatic inhibitory cell types and their different modulation by cholinergic receptor activation in the CA3 region of the mouse hippocampus. Eur. J. Neurosci. 31, 2234-2246. doi: 10.1111/j.14609568.2010.07292.x

Taffe, M. A., Weed, M. R., and Gold, L. H. (1999). Scopolamine alters rhesus monkey performance on a novel neuropsychological test battery. Brain Res. Cogn. Brain Res. 8, 203-212. doi: 10.1016/s0926-6410(99)00021-x

Thiele, A., Herrero, J. L., Distler, C., and Hoffmann, K. P. (2012). Contribution of cholinergic and GABAergic mechanisms to direction tuning, discriminability, response reliability and neuronal rate correlations in macaque middle temporal area. J. Neurosci. 32, 16602-16615. doi: 10.1523/JNEUROSCI.0554 $-12.2012$

Tikhonova, T. B., Miyamae, T., Gulchina, Y., Lewis, D. A., and GonzalezBurgos, G. (2018). Cell type- and layer-specific muscarinic potentiation of excitatory synaptic drive onto parvalbumin neurons in mouse prefrontal cortex. eNeuro 5:ENEURO.0208-18.2018. doi: 10.1523/ENEURO.0208-18.2018
Timbie, C., and Barbas, H. (2014). Specialized pathways from the primate amygdala to posterior orbitofrontal cortex. J. Neurosci. 34, 8106-8118. doi: 10.1523/JNEUROSCI.5014-13.2014

Timbie, C., and Barbas, H. (2015). Pathways for emotions: specializations in the amygdalar, mediodorsal thalamic and posterior orbitofrontal network. J. Neurosci. 35, 11976-11987. doi: 10.1523/JNEUROSCI.2157-15.2015

Tremblay, R., Lee, S., and Rudy, B. (2016). GABAergic interneurons in the neocortex: from cellular properties to circuits. Neuron 91, 260-292. doi: 10.1016/j.neuron.2016.06.033

Veith, V. K., Quigley, C., and Treue, S. (2021). Cholinergic manipulations affect sensory responses but not attentional enhancement in macaque MT. BMC Biol. 19:49. doi: 10.1186/s12915-021-00993-7

Vijayraghavan, S., and Everling, S. (2021). Neuromodulation of persistent activity and working memory circuitry in primate prefrontal cortex by muscarinic receptors. Front. Neural Circuits 15:648624. doi: 10.3389/fncir.2021.648624

Vijayraghavan, S., Major, A. J., and Everling, S. (2018). Muscarinic M1 receptor overstimulation disrupts working memory activity for rules in primate prefrontal cortex. Neuron 98, 1256-1268.e4. doi: 10.1016/j.neuron.2018.05.027

Voloh, B., Valiante, T. A., Everling, S., and Womelsdorf, T. (2015). Theta-gamma coordination between anterior cingulate and prefrontal cortex indexes correct attention shifts. Proc. Natl. Acad. Sci. U S A 112, 8457-8462. doi: 10.1073/pnas. 1500438112

Wang, J., John, Y., and Barbas, H. (2021). Pathways for contextual memory: the primate hippocampal pathway to anterior cingulate cortex. Cereb. Cortex 31 , 1807-1826. doi: 10.1093/cercor/bhaa333

Westerink, R. H., Beekwilder, J. P., and Wadman, W. J. (2012). Differential alterations of synaptic plasticity in dentate gyrus and CA1 hippocampal area of Calbindin-D28K knockout mice. Brain Res. 1450, 1-10. doi: 10.1016/j.brainres. 2012.02.036

Woo, T. U., Whitehead, R. E., Melchitzky, D. S., and Lewis, D. A. (1998). A subclass of prefrontal gamma-aminobutyric acid axon terminals are selectively altered in schizophrenia. Proc. Natl. Acad. Sci. U S A 95, 5341-5346. doi: 10.1073/pnas. 95.9.5341

Woodruff, A. R., McGarry, L. M., Vogels, T. P., Inan, M., Anderson, S. A., and Yuste, R. (2011). State-dependent function of neocortical chandelier cells. J. Neurosci. 31, 17872-17886. doi: 10.1523/JNEUROSCI.3894-11.2011

Yamasaki, M., Matsui, M., and Watanabe, M. (2010). Preferential localization of muscarinic M1 receptor on dendritic shaft and spine of cortical pyramidal cells and its anatomical evidence for volume transmission. J. Neurosci. 30, 4408-4418. doi: 10.1523/JNEUROSCI.5719-09.2010

Zaitsev, A. V., Gonzalez-Burgos, G., Povysheva, N. V., Kroner, S., Lewis, D. A., and Krimer, L. S. (2005). Localization of calcium-binding proteins in physiologically and morphologically characterized interneurons of monkey dorsolateral prefrontal cortex. Cereb. Cortex 15, 1178-1186. doi: 10.1093/cercor/bhh218

Zhou, X., Qi, X. L., Douglas, K., Palaninathan, K., Kang, H. S., Buccafusco, J. J., et al. (2011). Cholinergic modulation of working memory activity in primate prefrontal cortex. J. Neurophysiol. 106, 2180-2188. doi: 10.1152/jn. 00148.2011

Zikopoulos, B., and Barbas, H. (2007). Parallel driving and modulatory pathways link the prefrontal cortex and thalamus. PLoS One 2:e848. doi: 10.1371/journal. pone. 0000848

Conflict of Interest: The authors declare that the research was conducted in the absence of any commercial or financial relationships that could be construed as a potential conflict of interest.

Publisher's Note: All claims expressed in this article are solely those of the authors and do not necessarily represent those of their affiliated organizations, or those of the publisher, the editors and the reviewers. Any product that may be evaluated in this article, or claim that may be made by its manufacturer, is not guaranteed or endorsed by the publisher.

Copyright $\odot 2022$ Tsolias and Medalla. This is an open-access article distributed under the terms of the Creative Commons Attribution License (CC BY). The use, distribution or reproduction in other forums is permitted, provided the original author(s) and the copyright owner(s) are credited and that the original publication in this journal is cited, in accordance with accepted academic practice. No use, distribution or reproduction is permitted which does not comply with these terms. 